\title{
Uma Nova Versão Sobre a Oferta de Moeda no Plano de Ação Econômica do Governo (PAEG)
}

\author{
Cláudio Ribeiro Lucinda \\ Paulo Roberto Arvate
}

\author{
FGV/EESP e EAESP e do lbemec/SP \\ FGV/EESP e EAESP
}

\begin{abstract}
RESUMO
O controle da oferta de moeda foi um dos principais instrumentos na execução da política monetária desenhada pelos gestores do PAEG (1964/66). Embora a inflação tenha sido controlada, as metas previstas de execução monetária não foram alçadas. Pastore (1973, 1973a), Lara Resende (1982) e Cysne (1993) discordam, ora dos motivos, ora do momento em que os fatos ocorreram. Com a técnica de séries de tempo foi possível investigar o que de fato ocorreu. Como resultado desta investigação, durante o PAEG: a) apenas uma mudança importante ocorreu na oferta de moeda (julho de 1965). Se outras mudanças ocorreram, elas foram antes ou depois do plano; b) apesar dos autores concordarem com o papel do financiamento monetário do Caixa do Tesouro, o crédito concedido pelo Banco do Brasil enquanto Autoridade Monetária é o maior candidato para explicar o descontrole da oferta de moeda durante o plano; c) o crédito dado pelos Bancos Comerciais ao setor privado não teve qualquer papel no descontrole da oferta de moeda durante o plano e d) o papel das resenvas internacionais descrito pelos autores não foi o que de fato ocorreu. A utilização de dados de reservas que não aqueles disponibilizados pela SUMOC em termos reais impossibilitou um trabalho mais adequado por parte dos autores.
\end{abstract}

\section{PALAVRAS-CHAVE}

Plano de Ação Econômica do Governo (PAEG), oferta de moeda

ABSTRACT

The control of the money supply was one of the most important instruments used in the carrying out of the monetary policy designed by the author of PAEG (1964//966). Although the inflation has been controlled, the targets for monetary supply have not been reached. Pastore (1973, 1973a), Lara Resente (1982) and Cysne (1993) disaggee both on the reasons for that and the timing of the relevant facts. With a Time Series analysis it was possible to investigate what really happened with the money supply. The main conclusions are: a) During the PAEG, only one important structural change had happened (July (965); other breaks have happened before the plan; b) although all of these authors agree with the role played by the money financing of Treasury, the credit supplied by Banco do Brasil as Monetary Authority is the best candidate in explaining the behavior of the Money Supply during the plan; c) the credit supplied by the Commercial Banks to the private sector had not any role in the determination of money supply during the period and d) the role of international reserves described by the authors is dif-

ferent from what really happened. The use of data on reserves other than those made available by SUMOC in real terms turned impossible a more precise work by these authors.

KEY WORDS

Plano de Ação Econômica do Governo (PAEG), money supply

JEL Classification

E5 I

EST. ECON., SÃO PAULO, V. 35, N. 3, P. 391-431, JULHO-SETEMBRO 2005 


\section{INTRODUÇÃO}

O Programa de Ação Econômica do Governo (1964/1966) foi elaborado pelo Ministério do Planejamento e Coordenação Econômica para o governo militar empossado em 1964. Seu objetivo era resolver os problemas identificáveis da economia brasileira naquele momento. ${ }^{l}$ Resumidamente, na visão dos formuladores, os principais problemas seriam:

1. A inflação elevada gerada por causas tanto no lado da oferta como no lado da demanda agregada. Na oferta, por choques persistentes em razão da incompatibilidade entre os salários e a produtividade do fator trabalho. Na demanda, por descontrole fiscal, financiamento monetário e expansão do crédito;

2. A queda na taxa de crescimento do produto devido à reversão nos investimentos (de 10,3\% em 1961 para 1,6\% em 1963): esgotou-se o modelo de substituição de importações. ${ }^{2}$ Não havia mais espaço para crescer dentro deste modelo. Era necessário mudar o enfoque sobre o crescimento. Dever-se-ia buscar o crescimento num modelo impulsionado pelas exportações (a opção de um crescimento desvinculado de preocupações com a restrição externa levaria a problemas no Balanço de Pagamentos, o que, sem dúvida, seria um fator limitante para a sua continuidade). A busca de um maior realismo cambial foi o ponto de partida na construção desta política. 3,4

De qualquer forma, para resolver estes problemas foram relacionados objetivos e instrumentos que seriam utilizados. ${ }^{5}$ Especificamente no combate à inflação, os principais instrumentos utilizados para combatê-la foram, pelo lado da oferta, a fórmula salarial e, pelo lado da demanda, o controle do déficit, da emissão monetária e do crédito. Observando os instrumentos de política monetária utilizados para combater o cresci-

1 Para se ter uma idéia da situação da economia brasileira antes do PAEG, colocamos os resultados de inflação, taxa de crescimento do produto e o saldo do Balanço de pagamentos em Transações Correntes no Apêndice Al.

2 CYSNE (1993): "Reconhecendo a dificuldade de manutenção da politica de substituição de importações, na medida em que se esgotavam as possibilidades no setor de bens de consumo final e se tomava o rumo da substituição de matérias-primas, produtos intermediários e bens de capital até então importados, iniciava-se, a partir do PAEG, uma nova etapa na politica de comércio exterior brasileiro. Esta baseava num maior fomento às exportações, cuja receita, somada ao saldo líquido do balanço de capitais, era apresentada como condição necessária à manutenção do processo desenvolvimentista, na medida em que permitia ao pais a aquisição de produtos importados considerados essenciais ao desenvolvimento."

SERRA (1982) argumenta que houve um erro de interpretação dos formuladores do PAEG, uma vez que o que estava ocorrendo era o final de um ciclo de investimentos agravado pela inflação.

3 Não mudar apenas para ser baseado menos nas substituiçôes de importações e mais no incentivo às exportações, mas também menos concentrado geograficamente e espacialmente.

4 Como existia um desejo explícito de aumentar o nível de investimento e ao mesmo tempo reduzir a participação da poupança externa, o esforço público e privado em termos de poupança deveria ser muito maior.

5 Veja em LARA RESENDE (1982, p. 772). 
mento da inflação pelo lado da demanda, vê-se que a meta monetária a ser perseguida durante o PAEG não foi atingida, embora a inflação apresentasse tendência declinante. $^{6}$ Justificativas distintas para este resultado são encontradas tanto em Lara Resende (1982) como em Cysne (1993) ou Pastore (1973, 1973a). Basicamente, elas estão nos componentes que determinam a emissão monetária e no crédito. Sem dúvida, as distintas explicações sobre o não cumprimento destas metas motivaram nossa investigação e, delas, acabamos por construir o principal objetivo deste trabalho: verificar, com a utilização do instrumental de séries de tempo, o que de fato ocorreu com a oferta de moeda. Construiremos este objetivo em três seçôes seguidas a esta introdução. Na primeira, apresentaremos as divergências identificadas nos autores sobre o descontrole da oferta de moeda. Na segunda, faremos uma reconstrução empírica da oferta de moeda, não ficando especificamente no PAEG (trabalharemos entre os anos de 1960 e 1968 para verificar inclusive se o PAEG se constituiu numa mudança relevante na oferta). Testaremos se as mudanças descritas pelos autores nos componentes e na própria oferta de moeda foram relevantes. Por fim, encerraremos este trabalho ressaltando os pontos principais de nossa investigação. Faremos isto para que se tenha uma idéia mais clara sobre o que de fato aconteceu com a oferta de moeda. Sem dúvida, um dos principais itens da política monetária no PAEG.

\section{A VISÃO DE CYSNE, LARA RESENDE E PASTORE SOBRE OS DETERMI- NANTES DA OFERTA DE MOEDA DURANTE O PAEG}

O objetivo desta seção é apresentar a visão de Cysne (1993), Lara Resende (1982) e Pastore $(1973,1973 a)$ sobre os determinantes da oferta de moeda durante o PAEG (1964/1966). Ao final, destacaremos a diferença existente entre eles. Por oferta de moeda entender-se-á aqui o Ml (moeda em poder do público mais depósitos a vista) e pelos seus condicionantes, a base e o multiplicador monetário. Iremos analisar o comportamento da oferta de moeda como resultado do comportamento de seus determinantes. Nossa apresentação não seguirá a ordem cronológica dos trabalhos. Centralizamo-la naquilo que consideramos relevante em termos de argumentação e subsídio ao desenvolvimento empírico deste trabalho. Começaremos explorando o trabalho de Cysne (1993).

6 PASTORE (1973a) argumenta que a relação entre oferta de moeda e preços é uma tradição vinda da Teoria Quantitativa da Moeda. SARGENT \& WALLACE (1975) e SARGENT (1982) são exemplos também da relação entre o crescimento do estoque nominal de moeda e preços via mudanças na demanda agregada. 


\subsection{Fatores que Determinaram o Descontrole da Oferta de Moeda na Visão de Cysne}

Para Cysne (1993), o controle da oferta de moeda passa necessariamente pelo controle déficit público:

"O combate à inflação deve partir da progressiva contenção dos déficits governamentais. À União competirá o esforço inicial de sanear suas finanças, cortando despesas não prioritárias, corrigindo os déficits de autarquias $e$ de sociedades de economia mista (a fim de liberar recursos para investimentos básicos), racionalizando o sistema tributário e a sua arrecadação, $e$ restaurando o prestigio dos titulos puiblicos.”

Para se atingir este objetivo durante o PAEG foram fixadas metas em termos de déficit para os anos de 1964, 1965 e 1966, como se vê na tabela a seguir:

\section{TABELA 1 - PREVISÃO E METAS DE DÉFICIT DURANTE O PAEG}

\begin{tabular}{llc}
\hline Anos & & (Milhões de Cr\$) \\
\hline 1964 & Previsto & 753,3 \\
& Realizado & 728,2 \\
1965 & Previsto & 778 \\
& Realizado & 592,9 \\
1966 & & \\
& Previsto & 568,8 \\
& Realizado & 568,9 \\
\hline
\end{tabular}

Fonte: CYSNE (1993).

Percebe-se que a meta de déficit só não foi atingida em 1966, e por muito pouco. Nos dois anos iniciais, estiveram dentro do previsto. De qualquer forma, apesar da rubrica Realizado na Tabela 1 demonstrar um esforço fiscal, qualquer déficit per se tem que ser financiado por uma das fontes de financiamento existente: ou pela expansão monetária ou pela expansão do endividamento público. De fato, naquele período, a expansão monetária foi a forma escolhida como fonte de financiamento porque o Tesouro náo conseguiu financiar o seu déficit por endividamento público. Esta situação perdurou nos dois primeiros anos. Atingia-se a meta de déficit, mas não se conseguia evitar o financiamento monetário do mesmo até o final de $1965 .^{7}$ Mesmo assim, gostaríamos de deixar claro que a evolução do déficit, como proporção do PIB, foi cadente. É o que se pode observar na primeira coluna da Tabela 2, a seguir:

7 Os títulos públicos do Tesouro passaram a ser corrigido pela inflaçáo passada a partir do PAEG. Sem dúvida, isto melhorou as condiçốes de financiamento dos títulos emitidos. 
TABELA 2 - EVOLUÇÃO DO DÉFICIT E DA FORMA DE FINANCIAMENTO

\begin{tabular}{lcrrr}
\hline Anos & Déficit (\% do PIB) & Valor (Milhões de R\$) & $\begin{array}{c}\text { Financiamento } \\
\text { Autoridade Monetária }\end{array}$ & $\begin{array}{r}\text { Financiamento } \\
\text { Público }\end{array}$ \\
\hline 1963 & 4,2 & 504,7 & $426,4(84,5 \%)$ & $78,3(15,5 \%)$ \\
1964 & 3,2 & 728,2 & $736,4(101 \%)$ & $-8,2(-1 \%)$ \\
1965 & 1,6 & 592,2 & $269,7(45,5 \%)$ & $323,2(54,5 \%)$ \\
1966 & 1,1 & 586,6 & $-190,4(-3 \%)$ & $606,3(103 \%)$ \\
\hline
\end{tabular}

Fonte: CYSNE (1993) - Extraído de Conjuntura Econômica.

As duas últimas colunas nos dão idéia da mudança na forma de financiamento do déficit. É possível verificar que ao final do PAEG a condição necessária para se controlar a expansão monetária estava cumprida: o déficit (medido pelo caixa do Tesouro) estava integralmente financiado por dívida pública. O esforço mais difícil de se realizar foi atingido. Assim, se existisse um descontrole na mesma, esta razão estaria nas condições suficientes, não na condição necessária. Cysne (1993) enfatiza esta situação ao afirmar que o descontrole monetário esteve associado à meta monetária não atingida, não à existência de um déficit financiado monetariamente dentro da meta. Vejamos então, na Tabela 3, o previsto e o realizado em termos de expansão monetária:

TABELA 3 - PREVISÃO E REALIZAÇÃO DAS METAS MONETÁRIAS DURANTE O PAEG

\begin{tabular}{llc}
\hline Anos & & Emissão Monetária (\%)- $M_{1}$ \\
\hline 1964 & & 70 \\
& Previsto & 84,6 \\
& Realizado & \\
& & 30 \\
& Previsto & 76,5 \\
& Realizado & \\
& & 15 \\
& Previsto & 15,8 \\
\hline
\end{tabular}

Fonte: CYSNE (1993).

Pelo que se observa, apenas no ano de 1966 o previsto foi próximo ao realizado. Somente neste ano a expansão monetária esteve sob controle. Na versão de Cysne 
(1993), duas são as causas possíveis para o descumprimento do previsto: a) o comportamento do multiplicador monetário e b) o desarranjo institucional na Autoridade Monetária provocado pela duplicidade de atuação do Banco do Brasil. Falemos um pouco sobre cada uma das causas.

\subsubsection{O Multiplicador Monetário}

Para Cysne (1993), o multiplicador monetário foi fundamental na determinação da oferta de moeda porque é por intermédio dele que se observa a capacidade dos Bancos Comerciais em emprestar para o setor privado. Mesmo que exista um controle da base monetária, um controle da oferta de moeda pressupóe um controle do multiplicador:

"a politica de crédito às empresas deveria [grifo nosso] ser suficientemente controlada, para impedir os excessos da inflação de procura, mas suficientemente realista para adaptar-se à inflação de custo. Dentro desse princípio, os tetos globais de crédito às empresas deverão ser reajustados proporcionalmente ao crescimento do Produto Nacional a preços correntes ou, numa hipótese quantitativa mais facilmente programável, ao crescimento do total de meios de pagamentos. Esse critério destina-se a evitar os efeitos depressivos de uma contínua compressão real de crédito às empresas. Sua adoção não implica em nenhum círculo vicioso, mas apenas no tratamento do crédito ao setor privado como uma variável induzida ao processo de estabilização. Na medida em que se reduzem os déficits, on que se expandam além do previsto os recursos não monetários para o seu financiamento, reduzir-se-á proporcionalmente a expansão de crédito ao setor privado."

Ao que parece, o mesmo não foi controlado e prejudicou a execução da meta monetária:

"Este multiplicador, suposto constante na programação do PAEG, elevouse de 3,76 em dezembro de 1964 para 4,39 em dezembro de 1965. Apenas em 1966 sua alteração veio a facilitar o controle monetário (este foi também o ano de menor desvio e maior sucesso na condução da politica monetária), quando então sofreria uma redução acentuada, de 4,39 para 3,84.”

Passemos a segunda causa, o desarranjo institucional. 


\subsubsection{O Desarranjo Institucional na Autoridade Monetária}

Erros de avaliação sobre o comportamento da oferta de moeda durante o PAEG podem ser cometidos caso não se tenha clareza sobre a natureza da relação entre o Banco do Brasil e a SUMOC (Superintendência da Moeda e do Crédito). O Banco do Brasil, além de ser um Banco Comercial, realizava gastos de natureza fiscal com aporte direto da SUMOC. Neste caso, tanto o Banco do Brasil como a SUMOC eram considerados Autoridade Monetária:

"No periodo em que o Banco do Brasil era considerado Autoridade Monetária, por exemplo, destacavam-se como recursos das Autoridades Monetárias os depósitos em moeda estrangeira, a arrecadação do IOF (atribuida ao Bacen como reserva monetária), bem como as quotas cobradas aos exportadores de certos produtos, particularmente o café. Entre as aplicacốes, pode-se mencionar os repasses dos recursos do IOF ao BNDES e outras instituições, sob a forma de empréstimos a longo prazo; os empréstimos especiais à agricultura e à sustentação da politica de preços minimos, etc. ."8

Com ajuda da Tabela 4 poderemos mostrar melhor esta disfunção diante do que se entende por um Banco Central moderno. Nela apresentamos o Balancete da Autoridade Monetária:

TABELA 4 - O BALANCETE SIMPLIFICADO DA AUTORIDADE MONETÁRIA

\begin{tabular}{ll}
\hline Ativo & Passivo \\
\hline Contas Típicas de Banco Central & Contas Típicas de Banco Central \\
Reservas Internacionais & Saldo do Papel-Moeda Emitido \\
Empréstimos ao Tesouro Nacional & Depósitos do Tesouro Nacional \\
Redescontos e outros Empréstimos aos Bancos Comerciais & Depósitos dos Bancos Comerciais \\
Títulos Públicos Federais & \\
Outras Aplicações & \\
Contas Típicas de Banco Comercial & \\
Contas Especiais & Contas Típicas de Banco Comercial \\
Aplicações Especiais & Contas Especiais \\
\hline
\end{tabular}

Fonte: SIMONSEN \& CYSNE (1992).

8 Veja SIMONSEN \& CYSNE (1992, cap. 1). 
No que se denominou "Contas típicas do Banco Central", constam os registros contábeis encontrados em qualquer Banco Central do mundo. Apesar de não apresentarmos a lógica de financiamento monetário do déficit por meio do Balancete, é possível ver agora que uma expansão em Empréstimos ao Tesouro Nacional (Ativo), tudo o mais constante, levaria a uma expansão no Saldo de Papel-Moeda Emitido (Passivo). As Aplicações Especiais é que caracterizam a disfunção entre a SUMOC e o Banco do Brasil no âmbito da Autoridade Monetária. A movimentação nesta conta no lado do Ativo provoca, evidentemente, movimentaçôes no passivo monetário. ${ }^{9}$ Por ela, realizava-se parte do orçamento fiscal dentro do orçamento monetário. Por isto, é importante considerá-la ao se investigar o descontrole da oferta de moeda durante o PAEG. ${ }^{10}$ Vejamos qual seria a posição de Lara Resende (1993) sobre o descontrole monetário.

\subsection{Fatores que Determinaram o Descontrole da Oferta de Moeda na Visão de Lara Re- sende}

Como Lara Resende (1982) apresenta os mesmos dados sobre o comportamento do déficit (caixa do Tesouro) e seu financiamento que foram vistos na Tabela 2, o problema do descumprimento da meta monetária antes de 1966, na sua visão, deveu-se exclusivamente ao movimento nas Reservas Internacionais. ${ }^{11}$ Houve uma forte entrada de capital durante o PAEG, que, somada à melhora da Balança Comercial, gerou saldos positivos no Balanço de Pagamentos. ${ }^{12}$ Isto determinou um acúmulo de reservas (como os itens Reservas Internacionais e Meios de Pagamento na Tabela 5, a seguir, indicariam): ${ }^{13}$

\section{"A principal razão para este grau de descalibragem na politica monetá- ria [Tabela 5, grifo nosso] parece ter sido o resultado do Balanço de Pagamentos.”}

9 Como o Banco do Brasil também é a Autoridade Monetária, não se pode deixar de mencionar que os depósitos a vista nele realizados (se olharmos apenas M1) estão no passivo deste Balancete (Depósitos dos Bancos Comerciais). Como ele é Autoridade Monetária, os depósitos a vista que ocorreram nesta instituição são depósitos diretos na Autoridade Monetária, acabando por reduzir o efeito do multiplicador (há menos recursos para crédito). Devido a isto, PASTORE (1973a) acabou por mudar a fórmula do multiplicador, como veremos a seguir. Não basta trabalhar a questão apenas pelo lado do Ativo.

10 As contas que compõem as aplicações especiais ficarão destacadas na exposição que faremos sobre PASTORE $(1973,1973 a)$.

11 Veja Tabela 10, na p. 781, do artigo de LARA RESENDE(1982).

12 LARA RESENDE (1982): "A AID concedeu importantes empréstimos ao Brasil, que, durante o periodo 1964/ 67, foi o quarto maior receptor mundial de ajuda líquida ..."

13 LARA RESENDE (1982): "As reservas dobraram, passando de 245 para 484 milhóes de dólares. A politica monetária não foi suficientemente ágil para esterilizar este influxo de moeda gerado pelo superávit externo, e até o primeiro trimestre de 1966 a liquidez real da economia esteve folgada. A partir do segundo semestre de 1966, a politica monetária foi invertida, tornando-se apertada." 
Além das reservas em milhões de dólares, destaca-se na Tabela 5 a liquidez real dividida em três indicadores: Meios de Pagamento $\left(M_{1}\right)$, Empréstimos ao Setor Privado e os Empréstimos de Bancos Comercias ao Setor Privado. TABELA 5 - ÍNDICES DE LIQUIDEZ REAL, TAXAS DE CRESCIMENTO REAL
NOS ÚLTIMOS 12 MESES - 1964-1967(\%)

\begin{tabular}{|c|c|c|c|c|c|}
\hline \multicolumn{2}{|c|}{ Anos e Trimestres } & \multirow[t]{2}{*}{ Reservas Int. } & \multirow{2}{*}{$\begin{array}{r}M_{1} \\
-6\end{array}$} & \multirow{2}{*}{$\begin{array}{c}\begin{array}{c}\text { Emp. ao Setor } \\
\text { Privado }\end{array} \\
-14\end{array}$} & \multirow{2}{*}{$\begin{array}{c}\text { Emp. de Bancos Comerciais } \\
\text { ao Setor Privado } \\
-15\end{array}$} \\
\hline 1964 & $\mathrm{I}$ & & & & \\
\hline & II & & 2 & -4 & -1 \\
\hline & III & & 0 & 1 & 5 \\
\hline & IV & 245 & -7 & -7 & -6 \\
\hline \multirow[t]{4}{*}{1965} & 1 & & 9 & 2 & 5 \\
\hline & ॥ & & 17 & 6 & 15 \\
\hline & III & & 30 & 12 & 23 \\
\hline & IV & 484 & 42 & 25 & 41 \\
\hline \multirow[t]{4}{*}{1966} & I & & 21 & 16 & 28 \\
\hline & II & & 1 & 8 & 9 \\
\hline & III & & -12 & 1 & -3 \\
\hline & IV & 425 & -17 & -2 & -9 \\
\hline \multirow[t]{4}{*}{1967} & I & & -5 & 2 & -4 \\
\hline & $\|$ & & 10 & 14 & 14 \\
\hline & III & & 18 & 10 & 22 \\
\hline & IV & 199 & 20 & 26 & 33 \\
\hline
\end{tabular}

Fonte: LARA RESENDE (1982).

Para descaracterizar o impacto do Banco do Brasil no descontrole monetário, jogando mais força no seu argumento sobre o movimento das Reservas, Lara Resende (1982) argumentou que o Banco do Brasil só interferiu neste processo após o segundo semestre de 1966. Antes disto, a série dos Empréstimos ao Setor Privado, na qual o banco influenciaria, acompanhou o movimento da série correspondente aos Meios de Pagamento. Vamos aos motivos apresentados por Pastore (1973, 1973a). 


\subsection{Fatores Que Determinaram o Descontrole da Oferta de Moeda na Visão de Pastore}

Pastore (1973, 1973a) apresenta uma versão mais elaborada sobre os efeitos da disfunção entre a SUMOC e o do Banco do Brasil do que a vista em Cysne (1993). Nossa afirmação está baseada em dois fatos.

Em primeiro lugar, o cálculo do multiplicador monetário apresentado por ele incorpora a capacidade do Banco do Brasil atuar ora como Autoridade Monetária ora como Banco Comercial. Analisando a questão apenas em termos de $M_{1}$ (saldo do Papel Moeda em Poder do Público mais Depósitos a Vista), a relação entre $M_{1}$ e a Base Monetária $(B)$ seria dada por:

$$
M_{1}=m \times B
$$

E o multiplicador seria:

$$
m=\frac{1}{f+r(1-f)}
$$

Em que:

- $f$ é a proporção do total dos ativos monetários que o público retém sob a forma de papel-moeda;

- $r$ é a proporção dos depósitos a vista que os Bancos Comerciais retêm na forma de reservas voluntárias e compulsórias.

Mas ao se considerar a disfunção, o multiplicador seria: ${ }^{14}$

$$
m=\frac{f(1-\theta)}{r_{v}+r_{c}(1-\theta)+b+f(1+b)}
$$

Em que:

- $r_{c}$ e $r_{p}$ definem as taxas de reservas voluntárias e compulsórias, respectivamente;

- $\theta$ é a proporção de depósitos compulsórios que podem ser recolhidos em títulos governamentais;

- $b$ é a relação entre os depósitos do público no Banco do Brasil e nos Bancos Comerciais;

14 Veja o desenvolvimento do multiplicador em PASTORE (1973). 
- $f$ é a proporção do total dos ativos monetários que o público retém sobre a forma de papel-moeda.

Os multiplicadores contidos nas equações $\mathbf{2}$ e $\mathbf{3}$ diferem em relação aos seguintes aspectos: uma parte das reservas compulsórias pode ficar sob a forma de títulos públicos (forçando-nos a uma divisão no $r$ para que isto fique mais explícito) e a parte dos depósitos a vista que vão para o Banco do Brasil (esta decisão do público, que também pode ser influenciada pela política de captação do banco; no multiplicador esta decisão é vista na variável $b$ ). Estes efeitos reduzem o poder do multiplicador porque devolvem parte dos recursos obtidos na forma de depósito a vista para a Autoridade Monetária. ${ }^{15,16}$

Em segundo lugar, a variação da base monetária é resultado de seus diferentes componentes, inclusive aqueles que resultam da disfunção entre a SUMOC e o Banco do Brasil. ${ }^{17}$ É o que se pode observar na Tabela 6, retirada de Pastore (1973), entre os anos de 1964 e $1966:^{18}$

15 Este multiplicador difere um pouco do apresentado em PASTORE (1973, 1973a) por não apresentar no denominador a proporção de depósitos a vista sobre depósitos a prazo. Apesar de toda a disfunção, não nos pareceu adequado manter no multiplicador monetário utilizado para chegarmos a $M_{1}$, a utilização da possibilidade de depósitos a prazo. Basta transformar o termo denotado $a$ ali existente em zero.

16 Naquele momento era possível reter parte do compulsório em Títulos da dívida pública.

17 Grande parte das contas apresentadas aqui foi destacada na Tabela 4 como Aplicaçôes Especiais.

18 PASTORE (1973) estimou a variação das reservas pelo seguinte procedimento:

"a) tomou-se o valor das reservas em dólares publicado mensalmente no International Financial Statistics. A série utilizada foi a de foreign currency, que denominamos $R t$; foram calculados os acréscimos mensais dessa conta, $R t$, $e$ estes multiplicados pela taxa cambial vigente, $t$; e esse produto nos formece o fluxo em cruzeiros das reservas que são os fluxos que efetivamente exercem pressão monetária; b) para obter o saldo da conta ao longo do tempo precisamos apenas do saldo em um mês, que foi obtido no primeiro trimestre de 1970, fornecido pelo próprio Departamento Econômico do Banco Central." 
TABELA 6 - TAXAS ANUAIS (EM FINAL DE TRIMESTRE) DA VARIAÇÃO DA BASE E DE SEUS COMPONENTES (1964-1966)

\begin{tabular}{ccccccccccc}
\hline Períodos & Base & $\begin{array}{c}\text { Déficitde } \\
\text { Caixado } \\
\text { Tesouro }\end{array}$ & $\begin{array}{c}\text { Colocação de } \\
\text { Títulos Junto } \\
\text { ao Público }\end{array}$ & $\begin{array}{r}\text { Empréstimosdo } \\
\text { Banco do Brasil } \\
\text { ao Público }\end{array}$ & $\begin{array}{r}\text { Redes- } \\
\text { conto Ex- } \\
\text { ceto Café }\end{array}$ & $\begin{array}{r}\text { Preços } \\
\text { Mínimos }\end{array}$ & $\begin{array}{r}\text { Conta } \\
\text { Café }\end{array}$ & $\begin{array}{r}\text { Reservas } \\
\text { Estrangei- } \\
\text { ras Líquidas }\end{array}$ & $\begin{array}{r}\text { SaldoLíquido } \\
\text { das Demais } \\
\text { Contas }\end{array}$ \\
\hline 1964 & I & 0,881 & 0,626 & $-0,061$ & 0,265 & 0,021 & 0,006 & $-0,038$ & $-0,04$ & 0,12 \\
& II & 0,977 & 0,677 & $-0,015$ & 0,308 & 0,042 & 0 & $-0,018$ & $-0,012$ & $-0,005$ \\
& III & 0,931 & 0,656 & 0,042 & 0,314 & 0,032 & 0,002 & $-0,009$ & 0,057 & $-0,162$ \\
& IV & 0,887 & 0,423 & 0,029 & 0,316 & 0,06 & 0,004 & $-0,076$ & 0,132 & $-0,017$ \\
1965 & I & 0,797 & 0,373 & 0,015 & 0,268 & 0,003 & 0,007 & $-0,066$ & 0,214 & $-0,016$ \\
& II & 0,816 & 0,323 & $-0,016$ & 0,208 & $-0,015$ & 0,054 & $-0,072$ & 0,275 & 0,059 \\
& III & 0,819 & 0,244 & $-0,056$ & 0,151 & $-0,007$ & 0,108 & $-0,066$ & 0,26 & 0,183 \\
& IV & 0,675 & 0,181 & $-0,101$ & 0,101 & $-0,015$ & 0,079 & 0,042 & 0,212 & 0,174 \\
& I & 0,66 & 0,136 & $-0,1224$ & 0,099 & 0,016 & 0,064 & 0,039 & $-0,008$ & 0,38 \\
& II & 0,458 & 0,101 & $-0,154$ & 0,126 & 0,023 & 0,035 & $-0,009$ & $-0,063$ & 0,368 \\
& III & 0,3 & 0,115 & $-0,131$ & 0,121 & 0,011 & 0,013 & $-0,028$ & $-0,084$ & 0,253 \\
& IV & 0,216 & 0,106 & $-0,094$ & 0,155 & 0,031 & $-0,001$ & $-0,066$ & $-0,113$ & 0,198 \\
\hline
\end{tabular}

Fonte: PASTORE (1973).

O multiplicador monetário calculado por Pastore (1973) para o $M_{1}$ permanece estável para o período compreendido pelo PAEG (1964/66), como se pode observar na Tabela 7 , a seguir: ${ }^{19}$

\section{TABELA 7 - O MULTIPLICADOR MONETÁRIO}

\begin{tabular}{llc}
\hline Períodos & & Multiplicador \\
\hline 1964 & I & 1,62 \\
& II & 1,65 \\
& III & 1,64 \\
1965 & IV & 1,63 \\
& I & 1,65 \\
& II & 1,67 \\
& III & 1,66 \\
1966 & IV & 1,70 \\
& I & 1,63 \\
& II & 1,63 \\
& III & 1,61 \\
& IV & 1,60 \\
\hline
\end{tabular}

Fonte: PASTORE (1973).

19 Observe que neste multiplicador PASTORE (1973) considerou o termo a (proporção de depósitos a vista sobre outros depósitos). 
Considerando o comportamento do multiplicador exposto na Tabela 7, podemos nos concentrar nas causas da expansão da base monetária durante o PAEG. A variação da Base Monetária sofreu influência do Déficit de Caixa do Tesouro, da capacidade do Tesouro em obter financiamento direto do público (Colocação de Títulos com o Público), dos Empréstimos do Banco do Brasil ao setor Privado (enquanto o mesmo cumpria função de Autoridade Monetária) e da Movimentação das Reservas Estrangeiras Líquidas.

Excetuando-se os três primeiros trimestres de 1964, o Déficit de Caixa do Tesouro foi sendo reduzido gradativamente até o final do PAEG. Apesar da colocação de Títulos Públicos no início de 1964 não reduzir o impacto do déficit sobre a expansão da Base Monetária, ela passou, a partir daí, a reduzir este impacto de forma crescente. No ano de 1966, conseguiu-se neutralizar o efeito do déficit totalmente pela colocação de Títulos Públicos. Por outro lado, os empréstimos do Banco do Brasil ao setor Privado, enquanto o mesmo agia como Autoridade Monetária, mantiveram-se sem nenhuma inflexão aparente até o último trimestre de 1964. Isto ocorria em franca oposição ao movimento fiscal que acabamos de descrever. Do primeiro trimestre de 1965 até o primeiro trimestre de 1966 iniciou-se uma forte contração. A mesma dificuldade de se controlar a expansão da base é percebida quando se observa o movimento de Reservas Estrangeiras Líquidas entre o terceiro trimestre de 1964 e o último trimestre de 1965. Segundo Pastore (1973), o descontrole observado nas Reservas é fruto da Instrução 289 do Banco Central ("... permitiu operações financeiras entre firmas sediadas no Brasil e firmas estrangeiras, garantindo a compra de moeda estrangeira e a cobertura cambial no momento da liquidação da operação."). Como observação final, só podemos afirmar que a base monetária começou a ser reduzida, portanto controlada, depois do terceiro trimestre de 1965.

Passemos aos pontos de discordância entre eles, que no fundo vão alimentar nossa investigação empírica.

\subsection{Diferenças entre Cysne (1993), Lara Resende (1982) e Pastore (1973)}

Vamos apresentar as diferenças entre os três autores por tópicos para que a discussão nos sirva de embasamento para o trabalho empírico:

1. Para os três autores está claro que o déficit foi cadente e somente não provocou expansão monetária no ano de 1966. Se a redução do déficit era condição necessária para o controle da expansão monetária, ela foi cumprida durante o PAEG.

2. O papel das Reservas Internacionais no descontrole monetário durante o PAEG não foi investigado por Cysne (1993). Embora Pastore (1973,1973a) e Lara Resende 
(1982) apresentem medidas, justificativas e períodos de tempo distintos do impacto das Reservas sobre a expansão monetária, para ambos fica claro que, especificamente no ano de 1965, houve uma expansão monetária provocada por acúmulo das mesmas. Vamos apresentar um pouco mais a diferença entre eles neste ponto:

(a) Pastore $(1973,1973 a)$ estima trimestralmente em Cruzeiros o comportamento das Reservas enquanto Lara Resende (1982) apresenta apenas os valores anuais em milhões de dólares;

(b) Pastore $(1973,1973 a)$ justifica o acúmulo de Reservas pela instrução 289 do Banco Central. Lara Resende (1982) justifica-a pelo volume de recursos vindos da AID e atribui alguma importância ao resultado da Balança Comercial;

(c) Pastore $(1973,1973 a)$ mostra que a extensão cronológica deste efeito se deu entre o penúltimo trimestre de 1964 e o último trimestre de 1965. Para Lara Resende (1982) este efeito foi apenas no ano de 1965.

3. Em relação ao multiplicador monetário, podemos afirmar que Pastore (1973, 1973a) e Cysne (1993) diferem sobre o seu comportamento. Para o primeiro, o multiplicador foi estável e, para o segundo, ele não foi (cresceu entre 1964 e 1965, com uma pequena redução em 1966).

(a) Existem diferenças na fórmula de cálculo do multiplicador. Pastore (1973, 1973a) incorpora no cálculo do multiplicador a disfunção do Banco do Brasil como Autoridade Monetária (os depósitos no Banco do Brasil no passivo da Autoridade Monetária reduzem o impacto do multiplicador em relação à caracterização atual do mesmo). Cysne (1993) não considera a disfunção institucional no cálculo do multiplicador embora reconheça que a mesma exista na Autoridade Monetária;

(b) Lara Resende (1982) não faz nenhuma menção sobre a disfunção institucional.

4. Em relação ao crédito como um todo - o crédito concedido pelo Banco do Brasil ao setor Privado e o crédito concedido pelos Bancos Comerciais ao setor Privado temos posiçóes interessantes por parte dos autores:

(a) Cysne (1993) enfatiza que o descontrole monetário foi causado pelo Banco do Brasil antes de 1966 e pela manutenção do crédito concedido pelos Bancos Comerciais ao Setor Privado; 
(b) Lara Resende (1982) só concorda com o descontrole monetário provocado pelo Banco do Brasil a partir do primeiro trimestre de 1966;

(c) Pastore (1973, 1973a) considera os Empréstimos do Banco do Brasil entre os itens que pressionam a Base Monetária (devido à disfunção existente). Seus dados mostram que estes empréstimos permaneceram elevados ainda em 1964, caíram em 1965 e se estabilizaram em um patamar mais baixo em 1966.

Dado que não há divergências sobre os efeitos do déficit público em termos monetários, e existem divergências sobre os outros fatores determinantes da expansão monetária e o momento em que elas ocorreram, resolvemos, na seção seguinte, verificar o efeito de cada uma das variáveis apresentadas como relevantes pelos autores sobre o comportamento da oferta de moeda e estudar com mais precisão se os momentos apontados como mudanças são relevantes.

\section{A RECONSTRUÇÃO DA OFERTA DE MOEDA: OS RESULTADOS EMPÍRICOS}

Nesta seção iremos aplicar o instrumental mais moderno existente para a análise de séries temporais para investigarmos a relação existente entre a oferta de moeda no Brasil (definida como sendo o $M_{1}$ ) e as variáveis consideradas pela literatura como determinantes do comportamento da mesma. É sempre bom frisar que não existem divergências de importância e temporalidade sobre o papel do déficit (Caixa do Tesouro). Dado isto, resolvemos investigar o papel das variáveis apresentadas por Cysne (1993), Lara Resende (1982) e Pastore (1973,1973a) como fundamentais para a determinação do comportamento da oferta de moeda no período. Para tanto, utilizaremos uma especificação similar à desenvolvida por Brunner e Meltzer (1964) para investigar o comportamento da oferta de moeda. Tal especificação está baseada em uma relação como a exposta a seguir:

$$
M_{1 t}=f\left(X_{t}, B_{t}\right)
$$

Em que:

- $M_{1 t}$ denota a Oferta de Moeda, no caso o $M_{1}$.

- $B_{t}$ denota o Passivo Monetário das Autoridades Monetárias, também conhecido como Base Monetária. 
- $X_{t}$ denota o conjunto de variáveis que determinam o crédito dos Bancos Comerciais ao Setor Privado.

Esta função $f($.) pode assumir uma forma tal como a explicitada na equação 1 mais acima, ou algo mais complexo. Além disso, temos, de acordo com a Tabela 4, uma identidade entre o passivo monetário das Autoridades Monetárias e outras rubricas do balancete da mesma, da seguinte forma:

$$
B_{t}=g\left(Q_{t}\right)
$$

Em que $Q_{t}$ denota o conjunto de outras rubricas que queremos analisar. Substituindo $5 \mathrm{em} \mathrm{4}$, temos a seguinte relação que será a base de nossa análise empírica:

$$
M_{1 t}=f\left(X_{t}, g\left(Q_{t}\right)\right)
$$

A estimação econométrica da relação implícita pela equação 6 não é simples, e a obtenção de estimativas confiáveis para os parâmetros depende da superação de importantes obstáculos. Para tanto, realizaremos uma análise, em grande profundidade, dos dados primários.

Uma vez que estamos lidando com um período de inflação relativamente elevada, o primeiro cuidado a ser tomado envolve a investigação da estacionariedade das séries envolvidas. Para tanto, iremos realizar os principais testes de raiz unitária existentes na literatura para que possamos ter certeza da ordem de integração das séries de dados evitando assim um dos potenciais problemas associados com a utilização de tais variáveis, o da regressão espúria.

Outra característica do período, e que os autores mencionados nas seções anteriores deixam claro, é a elevada instabilidade em termos de comportamento da política econômica (e monetária) ao longo do período. Isto significa que mais um problema deve ser enfrentado - o da robustez dos resultados à existência de quebras estruturais. Um terceiro obstáculo, que resulta das características das séries monetárias, é a presença de um padrão sazonal significativo - o qual pode enviesar a análise de estacionariedade $\mathrm{e}$ demanda uma investigação mais aprofundada. $\mathrm{E}$, finalmente - antes que comecemos a análise econométrica da equação 6 , devemos investigar se a forma linear ou logarítmica é a mais adequada para a representação das séries envolvidas.

Quando da análise econométrica propriamente dita da equação 6, devemos inicialmente verificar se as séries possuem uma relação de longo prazo em comum - utilizando a terminologia da área, se as séries co-integram. No entanto, considerando as características das séries já discutidas acima, isto não é o suficiente. Ainda teremos que investigar 
a robustez da conclusão acerca da existência de relação de longo prazo à existência de padrões de sazonalidade das séries, bem como investigar a estabilidade desta relação de longo prazo durante o período analisado.

Estes passos foram seguidos ao longo da análise empírica, que será descrita a seguir. Comecemos pela análise dos testes de raiz unitária.

\subsection{Análise Univariada - Testes de Raiz Unitária}

Faz-se necessária inicialmente a descrição das variáveis utilizadas. Todas as variáveis a serem apresentadas a seguir possuem uma periodicidade mensal que vai de Janeiro de 1960 até Dezembro de 1968. Todas as séries estão expressas em milhares de Cruzeiros Novos deflacionados pelo IPA. ${ }^{20}$ As variáveis consideradas são:

- $C B C_{A M t}$ - é o crédito concedido aos bancos comerciais pela Autoridade Monetária (redescontos e outros tipos de empréstimos aos bancos comerciais). ${ }^{21}$

- $C B B_{A M t}$ - é o crédito concedido pela Autoridade Monetária via Banco do Brasil (entre as aplicações especiais, o crédito concedido via Banco do Brasil).

- $R_{t}$ - são as reservas internacionais existentes na conta da Autoridade Monetária.

- $C B C_{t}$ - é o crédito concedido pelos Bancos Comerciais ao setor privado (empréstimos de Bancos Comerciais ao setor privado).

- $L M_{1 t-}$ Oferta Monetária, medida como o Ml.

As estatísticas descritivas, bem como os gráficos das mesmas, estão presentes no Apêndice A.2. Construída a base de dados, o passo seguinte foi no sentido de analisar cada uma das variáveis individualmente. Inicialmente, foram realizados os seguintes testes de raiz unitária para estas séries:

- Teste de Dickey-Fuller Aumentado: ${ }^{22}$ baseia-se na regressão auxiliar envolvendo uma variável $y_{t}$, qualquer uma das mencionadas acima, segundo a forma $\Delta$ $y_{t}=\alpha+\beta_{0} t+\beta_{1} y_{t-1}+\sum_{i=1} K_{\gamma_{i}} \Delta y_{t-i}+\varepsilon_{t}$. Nesta regressão auxiliar é testada a hipótese $\beta_{0}=0,{ }^{23}$ definido o número $K$ de defasagens adicionais a serem incluídas no momento da estimação, de forma a assegurar que $\varepsilon_{t}$ seja um ruído branco.

20 O mesmo Índice de Preços utilizado por LARA RESENDE (1982) em sua análise.

21 Foi o único termo incluído na regressão que não faz parte da argumentação dos autores.

22 DICKEY \& FULLER (1979, 1981).

23 É importante notar que neste caso a distribuição estatística do coeficiente é diferente da distribuição t de Student tradicional 
- Teste de Dickey-Fuller Aumentado com Eliminação de Tendência por GLS: ${ }^{24}$ baseia-se em uma regressão auxiliar $\Delta y_{t}^{d}=\beta_{1} y_{t-1}{ }^{d}+\sum_{i=1} K_{i_{i}} \Delta y_{t-i}{ }^{d}+\varepsilon_{t}$, em que $y_{t}^{d}$ denota uma transformação da variável $y_{t}$ de tal sorte que os efeitos da constante e tendência são eliminados antes da realização da regressão auxiliar.

- Teste de Phillips-Perron: ${ }^{25}$ baseia-se em uma regressão auxiliar $\Delta y_{t}=\alpha+\beta_{0} t+\beta_{1} y_{t-1}+\varepsilon_{t}$ em que a estatística $t$ associada ao coeficiente $\beta_{1}$ é ajustada de tal sorte que a eventual correlação serial nos resíduos não afete os erros padrốes dos coeficientes.

- Teste de Kwiatkowski, Phillips, Schmidt e Schin: ${ }^{26}$ este teste difere dos anteriores na medida em que supõe-se que a série $y_{t}$ é assumida estacionária na hipótese nula. Este teste é baseado na regressão auxiliar $y_{t}=\alpha+\beta_{0} t+u_{t}$, em que os resíduos são utilizados no cálculo da estatística de teste.

- Teste Elliot, Rothemberg e Stock (Point Optimal Test): ${ }^{27}$ em uma estrutura em que o modelo para $y_{t}$ segue um $\operatorname{AR}(1)$ com variância unitária para os resíduos, $\mathrm{o}$ lema de Neyman-Pearson pode ser utilizado para construir um teste com maior poder contra uma alternativa específica. O teste se baseia em uma transformação específica de $y_{t}$ denominada quasi-diferenciação.

- Testes de Ng e Perron: ${ }^{28}$ tais testes são baseados na transformação por Mínimos Quadrados Generalizados (GLS) dos dados originais $y_{t}$.

Todos os testes foram realizados utilizando o pacote econométrico EViews, versão 4.1. Os resultados estão no Apêndice A.3. Os resultados ali presentes indicam que todas as variáveis são estacionárias em primeiras diferenças e não estacionárias quando consideradas em nível. A exceção é a variável $R_{t}$, cujos resultados dos testes ainda não são conclusivos: ora indicam estacionariedade em nível e ora indicam estacionariedade somente em primeiras diferenças.

Tendo analisado os resultados destes testes, uma questão adicional se coloca. Existe uma opinião disseminada entre os praticantes de análise econométrica aplicada à macroeconomia sobre a adequação da transformação logarítmica das variáveis. Entre outras razões, ela transforma uma eventual tendência exponencial nos níveis das variáveis em crescimento linear, a variância da série pode ser estabilizada, as observações aberrantes podem se tornar menos influentes e os parâmetros estimados para séries trans-

\footnotetext{
24 Mínimos Quadrados Generalizados (Generalized Least Squares-GLS). Para mais detalhes, consultar ELLIOTT, ROTHEMBERG \& STOCK (1996).

25 PHILLIPS \& PERRON (1988).

26 KWIATKOWSKI, PHILLIPS, SCHMIDT \& SCHIN (1992).

27 ELLIOT, ROTHEMBERG \& STOCK (1996).

28 NG \& PERRON (2001).
} 
formadas podem ter uma interpretação simples em termos de elasticidades. No entanto, não existe nenhuma razão teórica que justifique a transformação a priori em logaritmos. Além disso, algumas séries - a série de reservas internacionais em posse da Autoridade Monetária $\left(R_{t}\right)^{29}$ - apresentam valores negativos, o que faz com que a transformação logarítmica implique a eliminação de observações da amostra. Finalmente, esta transformação também possui efeito sobre a capacidade dos testes de raiz unitária em distinguir entre as hipóteses. (FRANSES \& McALEER, 1998a). Devido a isto, utilizamos o teste de Franses e McAleer (1998b) para avaliar a adequação da transformação logarítmica. Segundo estes autores, o procedimento de testes deve seguir os passos abaixo:

1. Determina-se o número de defasagens adicionais a serem incluídas na regressão auxiliar por meio do teste ADF tradicional supondo a transformação da variável (utilizando a mesma notação anteriormente utilizada para os testes de raiz unitária, supondo $\left.\ln \left(y_{t}\right)\right)$.

2. Para o número de defasagens determinado anteriormente, utilizar a seguinte regressão auxiliar, ${ }^{30}$ sendo que o termo $\psi_{i}$ denota uma combinação linear de coeficientes estimados em outras regressões auxiliares:

$$
\ln \left(y_{t}\right)=\psi_{0}+\psi_{1} \ln \left(y_{t-1}\right)+\psi_{2} t \psi_{3} \Delta \ln \left(y_{t-1}\right)+\psi_{4}\left(\Delta \ln \left(y_{t-1}\right)\right)^{2}
$$

3. Caso a hipótese $\psi_{4}=0$ seja rejeitada, então a transformação logarítmica da variável $y_{t}$ não é adequada e, portanto, não leva a uma inferência válida sobre a existência - ou não - de raiz unitária na mesma série.

4. Caso contrário, a transformação é adequada e o teste ADF deve ser realizado sobre a série transformada, $\ln \left(y_{t}\right)$.

A tabela a seguir mostra o resultado para as variáveis $C B C_{A M t}$ e $C B C_{t}$.

TABELA 8-ANÁLISE DE FRANSES E McALEER (1998B) - CBC ${ }_{A M T} E_{C B C_{T}}$

\begin{tabular}{lccc}
\hline Variável & Est. Teste & Valor Crítico & Conclusão \\
\hline$C B C_{A M t}$ & $-2,80$ & $-1,96$ & Não transformar \\
$C B C_{t}$ & 2,68 & 1,96 & Não Transformar \\
\hline
\end{tabular}

29 Segundo os dados da SUMOC/BACEN.

30 Neste caso, estamos supondo que somente uma defasagem da variável dependente entre os regressores já é suficiente para evitar problemas decorrentes da estrutura de resíduos sobre a estatística de teste. 
Os resultados da tabela acima também indicam que a transformação logarítmica destas variáveis não deve ser levada a cabo. Com relação às variáveis $L M_{1}$ e $C B B_{A M t}$, os testes de raiz unitária indicaram que o número de defasagens a ser adicionado na regressão de teste é igual a zero. Uma vez que a estatística de teste não segue uma distribuição tradicional neste caso, os autores (FRANSES \& McALEER, 1998b) afirmam que não é computacionalmente fácil realizar este procedimento. Desta forma, decidiu-se por manter estas variáveis sem realizar a transformação logarítmica. Com relação à variável $R_{t}$, devido à existência de valores negativos para a mesma, optou-se por mantê-la sem a transformação. Passemos à investigação acerca das quebras estruturais e dos padrões de sazonalidade.

\subsubsection{Testes de Quebra Estrutural}

Uma vez que o período analisado abarca um grande número de mudanças nos instrumentos de política, torna-se necessário investigar o efeito de eventuais quebras estruturais nos resultados dos testes de raiz unitária apresentados acima, pois as conclusões podem ser válidas somente para uma parte da amostra de dados. Para tanto, utilizamos o procedimento de Zivot e Andrews (1992, que endogeneiza a existência de eventuais quebras estruturais e escolhe os momentos em que a estatística do teste ADF é mais desfavorável à hipótese de existência de raízes unitárias. Evidentemente, os valores críticos deste teste são diferentes dos tradicionalmente utilizados nos testes ADF - veja Zivot e Andrews (1992).

As tabelas do Apêndice A.4 mostram os resultados para cada um dos testes de raiz unitária com quebra estrutural endógena propostos por Zivot e Andrews (1992). Estes resultados indicam que para todas as variáveis, exceto para a variável $R_{t}$, a conclusão da seção anterior com respeito à existência de raízes unitárias é robusta à premissa de imposição de uma quebra estrutural. O resultado da variável $R_{t}$ não é tão claro e demandará um tratamento mais cuidadoso, com os resultados indicando a existência de uma quebra estrutural na série em dezembro de 1965, conforme a figura no mesmo Apêndice A.4. Antes de passarmos para a análise das séries em conjunto - utilizando análise de co-integração - devemos investigar o papel dos padrões sazonais das séries. ${ }^{31}$

\subsubsection{Testes de Raiz Unitária Sazonal}

O passo seguinte da análise foi identificar a existência de padróes sazonais sobre cada uma das séries analisadas. Para tanto, foi aplicado o procedimento de Hylleberg, Engle, Granger e Yoo (1990), originalmente desenvolvido para a análise de séries trimestrais e

31 Existe uma opinião disseminada na literatura econométrica aplicada à Macroeconomia que as séries monetárias apresentam padrões sazonais que podem enviesar conclusões derivadas de análises que não levam este fato explicitamente em consideração. 
estendido por Beaulieu e Miron (1993) para o caso de séries mensais. Este procedimento é baseado na seguinte regressão auxiliar, estimada por Mínimos Quadrados Ordinários:

$$
\Delta_{12} y_{t}=\beta_{0}, \beta_{1} t+\sum_{k=1}^{12} \pi_{k} y_{k, t-1}+\sum_{k=1}^{12} \gamma_{k} S_{k t}+\varepsilon_{t}
$$

Em que:

- $\Delta_{12}=\left(1-L^{12}\right)-$ em que $L$ denota o operador defasagem. Ou seja, $\Delta_{12} y_{t}=y_{t}-y_{t-12}$.

- $t$ - Tendência temporal.

- $y_{k, t-1}$ - combinação linear de defasagens de $y_{t}$ que constituem soluções para a linearização de um polinômio de ordem 12 nas defasagens de $y_{t}$. Para representações exatas de cada $y_{k, t-1}$, ver Beaulieu e Miron (1993, p. 308).

- $S_{k t}$ - variável qualitativa com valor 1 para o mês $k$ e valor zero para o restante dos meses.

- $\beta_{0}, \beta_{1}, \pi_{k}, \gamma_{k}-$ coeficientes a serem estimados.

Para rejeitar a hipótese de existência de raiz unitária em cada uma das frequiências sazonais, $\pi_{k}$ não deve ser estatisticamente igual a zero para $k=2$ e para pelo menos um dos elementos dos pares $k=\{3,4\}, k=\{5,6\}, k=\{7,8\}, k=\{9,10\}, k=\{11,12\}$. As tabelas do Apêndice A.5 mostram os resultados dos testes para cada variável da amostra. Nestas tabelas, temos a indicação da existência de raízes unitárias sazonais nas freqüêencias $\pi, \pi / 2$ e $\pi / 6$ para as variáveis $C B C_{A M t}$ e $L M_{t}$. Com relação às demais variáveis, $C B B_{A M t}, C B C_{t} \mathrm{e}$ $R_{t}$, temos a indicação de raízes unitárias sazonais apenas nas freqüências $\pi \mathrm{e} \pi / 2$.

Resumindo as análises de estacionariedade das variáveis, temos que:

- Todos os testes de raiz unitária indicam a não rejeição da hipótese da existência de uma raiz unitária quando consideramos as séries em nível. Quando consideramos as séries em primeiras diferenças, a hipótese de existência de raiz unitária é rejeitada a $\mathbf{5 \%}$ de significância em todas as séries.

- O teste de Franses e McAleer (1998b) indica que a transformação logarítmica não deve ser aplicada para o caso das variáveis $C B C_{A M t}$ e $C B C_{t}$. Por outro lado, a série $R_{t}$, por envolver valores negativos, não foi transformada em logaritmos. Adicionalmente, o teste não pôde fornecer resultados conclusivos acerca da transfor- 
mação logarítmica para as séries $L M_{1 t}$ e $C B B_{A M t}$. Logo, todas as variáveis serão consideradas em nível na análise subseqüente.

- O teste de Zivot e Andrews (1992) indica que as conclusões dos testes de raiz unitária são robustas à hipótese de existência de quebras estruturais tanto no intercepto quanto na tendência, exceto para o caso da variável $R_{t}$. Este fato deverá ser levado em consideração quando da análise subseqüente, com a inclusão de uma variável dummy para representar tal quebra.

- Finalmente, o teste de Beaulieu e Miron (1993) indica que em todas as séries não pudemos rejeitar a hipótese de existência de raízes unitárias sazonais para as freqüências $\pi$ e $\pi / 2$. Para o caso das variáveis $C B C_{A M t}$ e $L M_{1 t}$, não pudemos rejeitar a hipótese de existência de uma terceira raiz unitária sazonal, para a freqüência $\pi / 6$.

\subsection{Análise de Co-integração}

Neste ponto do texto iremos analisar conjuntamente as variáveis mencionadas acima. Sendo mais específico, vamos verificar a natureza e o comportamento das relaçóes entre as variáveis. Inicialmente iremos realizar uma análise de co-integração ignorando a existência de raízes unitárias sazonais, modelando a sazonalidade por meio de variáveis dummy. Em um momento posterior, investigaremos a existência de co-integração sazonal, e como este fato afetaria nossas conclusões.

\subsubsection{Co-integração com Sazonalidade Determinística}

Replicaremos o procedimento de Johansen e Juselius (1990) para as variáveis estudadas. Este procedimento é baseado na estimação do seguinte sistema de Vetores AutoRegressivos (VAR):

$$
Y_{t}=\Gamma_{1} D_{1 t}+\Gamma_{2} D_{2 t}+\ldots+\Gamma_{12} D_{12 t}+\Pi Y_{t-p}+\Theta_{1} \Delta_{1} \Upsilon_{t-1}+\ldots+\Theta_{p-1} \Delta_{1} Y_{t-p+1}+\varepsilon_{t}
$$

Conforme Johansen e Juselius (1990), ${ }^{32}$ o procedimento de análise passa pela investigação do posto (número de colunas linearmente independentes) da matriz $\Pi$ Em especial, espera-se que esta matriz $\Pi$ tenha um posto menor do que o número de colunas

32 JOHANSEN \& JUSELIUS (1990) recomendam que se utilizem variáveis dummy centradas, ou seja, cuja soma ao longo da amostra seja igual a zero. Seguiremos este procedimento na presente análise na construção das variáveis $D_{i 1}$, com $i=1,2 \ldots 12$, uma vez que o mesmo garante as melhores propriedades assintóticas para a estatística de teste. 
existentes na mesma. A Tabela 9 mostra os resultados do teste de Johansen para as variáveis $C B C_{A M t}, C B C_{t}, L M_{1}, C B B_{A M t}$ e $R_{t}{ }^{33}$

TABELA 9 - RESULTADOS TESTE DE JOHANSEN - NÚMERO DE VETORES DE CORREÇÃO DE ERRO

\begin{tabular}{lccccc}
\hline & Sem Tend. I & Sem Tend. II & Tend. Linear I & Tend. Linear II & Tend.Quadrát. \\
\hline Est. Traço & 2 & 2 & 2 & 1 & 1 \\
Est. Autovalor & 2 & 2 & 2 & 2 & 1
\end{tabular}

Obs: Sem Tendência I - Modelo em que se assume ausência de intercepto e tendência tanto no sistema de Vetores Auto-regressivos quanto nos Vetores de Correção de Erro. Sem Tendência II Modelo em que se assume ausência de tendência tanto no sistema de Vetores Auto-regressivos quanto nos Vetores de Correção de Erro e somente intercepto nos Vetores de Correção de Erro. Tendência Linear I - Intercepto no Vetor de Correção de Erro e no sistema de Vetores Auto-regressivos. Tendência Linear II- Intercepto no Vetor de Correção de Erro e no sistema de Vetores Auto-regressivos. Tendência somente no Vetor de Correção de Erro. Tendência Quadrática - Intercepto e tendência no Vetor de Correção de Erro e no sistema de Vetores Auto-regressivos.

Temos na tabela a seguir as estimativas para os parâmetros da relação de longo prazo associada com estas variáveis - os coeficientes das variáveis associadas com o Vetor de Correção de Erros: ${ }^{34}$

\section{TABELA 10 - VETOR DE CORREÇÃO DE ERROS - ESTIMATIVAS}

\begin{tabular}{lrc}
\hline & Coeficiente & Erro-Padrão \\
\hline Constante & $-330,617$ & \\
$L M_{1 t}$ & 1 & \\
$C B C_{A M t}$ & $-1,7955$ & 2,0727 \\
$C B B_{t}$ & $-0,14202$ & 0,3818 \\
$C B B_{A M t}$ & $-0,7656^{*}$ & 0,1512 \\
$R_{t}$ & $-0,02428^{\star}$ & 0,00514
\end{tabular}

Obs: ${ }^{*}$ - Significante a $5 \%$.

33 Foi assumido um total de seis defasagens para as variáveis em primeira diferença, bem como 11 dummies sazonais centradas e uma dummy correspondente ao mês de dezembro de 1965, em que se indicou a quebra estrutural na série $R_{t}$ pelo teste de ZIVOT \& ANDREWS (1992)

34 É importante notar que este Vetor de Correção de Erros, bem como a especificação linear exibida a seguir, também podem ser entendidas como um caso especial da equação 6, supondo-se que somente as rubricas mencionadas na literatura tiveram algum papel sobre a evolução da oferta monetária. 
Uma consideração adicional deve ser feita antes que possamos considerar estes resultados como definitivos. Devido aos resultados do teste de co-integração, é elevada a probabilidade de existência de mais de uma relação de co-integração entre as variáveis. ${ }^{35}$ No caso em que existe mais de uma relação de co-integração, a análise fica mais complicada, uma vez que teremos mais de uma representação possível para a relação de longo prazo entre as variáveis. Um resultado apresentado em Hamilton (1994) garante a solução para este dilema. Segundo a proposição 19.3 de Hamilton (1994, p. 590), temos que, entre o conjunto de possíveis relações de co-integração, a estimação por Mínimos Quadrados Ordinários da forma funcional a seguir garante a escolha daquela cujos resíduos não são correlacionados com nenhuma outra combinação integrada de ordem 1 entre as variáveis do lado direito da relação (7).

$$
L M_{1 t}=\beta_{0}+\beta_{1} C B C_{A M t}+\beta_{2} C B C_{t}+\beta_{3} C B B_{A M t}+\beta_{4} R_{t}+u_{t}
$$

Neste sentido, foi estimada por Mínimos Quadrados Ordinários a mesma, cujos resultados estão abaixo:

\section{TABELA 11 - ESTIMATIVAS POR MÍNIMOS QUADRADOS ORDINÁRIOS DA RELAÇAO (7)}

\begin{tabular}{lcr}
\hline & Coeficiente & Erro-Padrão \\
\hline Constante & $-234,39$ & 73,304 \\
$C B C_{A M t}$ & $-0,5477$ & 0,4774 \\
CBB $_{t}$ & 0,2159 & 0,1094 \\
$C B B_{\text {AMt }}$ & $1,088^{\star}$ & 0,2006 \\
$R_{t}$ & $-0,0065^{\star}$ & 0,000792 \\
\hline
\end{tabular}

Obs: * - Significante a 5\%. Note-se que a representação na tabela é tal que os resultados das variáveis por construção - devem apresentar sinais opostos ao observado na tabela com o Vetor de Correção de Erros.

Podemos notar que os resultados da tabela acima mostram bastante consistência com o que foi observado para o caso do Vetor de Correção de Erros e com os coeficientes estimados tendo sinais e magnitudes similares. O passo seguinte da análise é investigar a existência de co-integração nas freqüências sazonais indicadas anteriormente.

35 Optou-se por não afirmar certeza porque em alguns casos a suposição de tendência ou intercepto no Vetor de Correção de Erros nos permitia concluir somente pela existência de uma relação de co-integração. 


\subsubsection{Co-integração com Sazonalidade Estocástica}

Considerando a existência de raízes unitárias sazonais mencionadas anteriormente, $\mathrm{e}$ em especial nas freqüências $\pi$ e $\pi / 2$, devemos ampliar a nossa análise de forma a considerar explicitamente a possibilidade de raízes unitárias sazonais e co-integração sazonal. Para tanto, utilizaremos um modelo de Vetores Auto-regressivos conforme o descrito em Lee (1992) (para o caso trimestral) e Martín e Díaz-Emparanza (1996) (para dados mensais). Para o caso de co-integração sazonal, o modelo de Vetores Autoregressivos tem a seguinte forma:

$$
\Delta_{12} \Upsilon_{t}=\Gamma_{1} \Delta_{12} \Upsilon_{t-1}+\ldots+\Gamma_{p-12} \Delta_{12} \Upsilon_{t-(p-12)}+\Pi_{1} \Upsilon_{1, t-1}+\Pi_{2} \Upsilon_{2, t-1}+\ldots+\Pi_{12} \Upsilon_{12, t-1}+\varepsilon_{t}
$$

em que as variáveis $\Upsilon$ são, na verdade, transformaçôes utilizando os operadores defasagem de cada uma das variáveis envolvidas na análise. Para detalhes sobre as transformações envolvidas - que são bastante similares às transformações desenvolvidas por Beaulieu e Miron (1993) para o caso de raízes unitárias sazonais no caso de observações mensais - recomenda-se Martín e Díaz-Emparanza (1996).

Uma vez que foi detectada a existência de raízes unitárias sazonais em todas as séries apenas nas freqüências $\pi$ e $\pi / 2$, devemos realizar o teste de co-integração somente para estas freqüências, bem como para a freqüência zero. Esta última equivale à análise de co-integração da seção anterior. A única diferença em relação a ele é que se considera explicitamente no procedimento de teste a existência de raízes unitárias sazonais em outras freqüências. Uma vez que somente estamos interessados em analisar estas freqüências, os outros resultados dos testes não serão reportados.

\section{TABELA 12 - RESULTADOS TESTE DE CO-INTEGRAÇÃO SAZONAL}

\begin{tabular}{lccc}
\hline & \multicolumn{3}{c}{ Freqüência } \\
\cline { 2 - 4 } & 0 & $\pi$ & $\pi / 2$ \\
\hline Número de Vetores de Co-integração & 2 & 3 & 2 \\
\hline
\end{tabular}

Podemos notar que a conclusão de co-integração na freqüência zero também se mantém quando consideramos explicitamente a existência de outras relaçóes de co-integração em outras frequiências. Portanto, os resultados expostos acima, para o caso de cointegração com sazonalidade determinística, continuam valendo. 


\subsection{A Estabilidade da Relação}

Antes de entrarmos na descrição destes resultados, dois pontos são de especial relevância. Em primeiro lugar, os autores mencionam a entrada do PAEG como sendo o momento de mudança na política monetária (a oferta de moeda é o principal instrumento desta política); além disso, todos os autores descrevem momentos específicos no tempo nos quais os componentes da oferta de moeda sofreram alteraçóes (semelhante à descrição que fizemos nas Tabelas 5 e 6 ).

Desta forma, é importante verificar se existe estabilidade em termos temporais nos coeficientes das variáveis que explicam a oferta. Esta estabilidade foi investigada por meio da utilização da estatística da razão de Verossimilhança de Quandt. ${ }^{36}$ Tal teste consiste na realização de um teste F para uma quebra estrutural em cada um dos instantes da amostra. Nos momentos em que a estatística de teste é superior ao valor crítico, podemos afirmar que existe uma quebra estrutural. ${ }^{37}$

O resultado da estatística de teste para a estabilidade da em cada um dos momentos é apresentado graficamente na figura a seguir:

\section{FIGURA 1 - RESULTADOS TESTE DE RAZÃO DE VEROSSIMILHANÇA DE QUANDT (RVQ)}

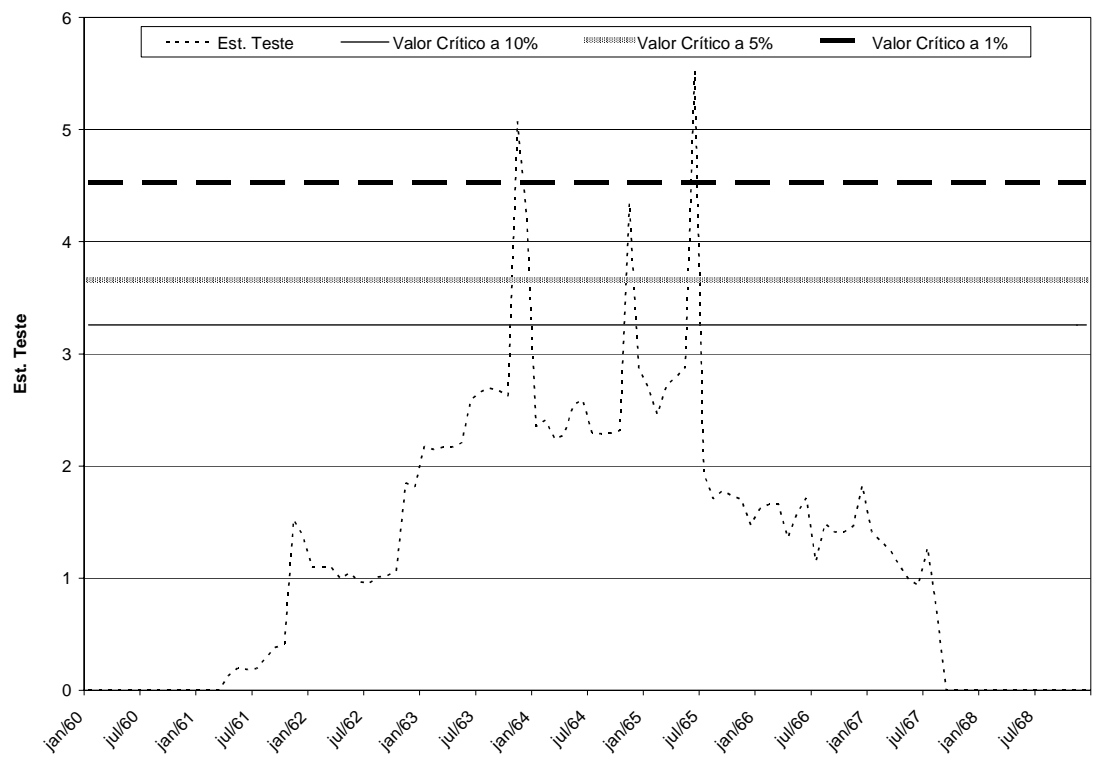

36 Recomenda-se ANDREWS (1993) para uma derivação das propriedades assintóticas da estatística de teste.

37 Em termos mais formais: a data em que a estatística $\mathrm{F}$ associada com o teste atinge um valor superior ao valor crítico é, sob determinadas condiçôes, um estimador consistente da data em que a quebra estrutural ocorreu. 
Chegamos à conclusão que dentro do nosso período de análise os coeficientes não são estáveis. Além disso, o gráfico mostra que existem três grandes períodos. O primeiro deles de janeiro de 1960 a novembro de 1963, o segundo de janeiro de 1964 a junho de 1965 e o terceiro de julho de 1965 a dezembro de 1968. Para cada um dos subperíodos, temos os seguintes resultados da estimação:

TABELA 13 - ESTIMAÇÃO EM TRÊS SUBPERÍODOS

\begin{tabular}{lccc}
\hline & \multicolumn{3}{c}{ Subperíodos } \\
\cline { 2 - 4 } & $1960: 01-1963: 11$ & $1964: 01-1965: 06$ & $1965: 07-1968: 12$ \\
\hline Constante & 108.675 & $272.727^{* *}$ & $338.826^{\star *}$ \\
CBC $_{\text {AMt }}$ & -1.571 & -2.318 & -12.315 \\
& 0.9512 & -16.277 & -0.8535 \\
CBB $_{\text {AMt }}$ & -1.553 & $(-0.800)$ & $(-1.069)$ \\
& $1.4902^{\star \star}$ & $1.5587^{\star \star}$ & $0.9547^{\star \star}$ \\
CBC $_{t}$ & -9.235 & -5.523 & -5.710 \\
& $0.1444^{\star}$ & -10.432 & 0.0156 \\
$R_{t}$ & -1.812 & $(-0.751)$ & $(0.035)$ \\
& -0.0011 & -0.0148 & $-0.0082^{\star \star}$ \\
\hline$R^{2}$ & $(-0.364)$ & $(-1.333)$ & $(-4.982)$ \\
$R^{2}$ Ajustado & 0.9203 & 0.889 & 0.964 \\
Durbin-Watson & 0.9103 & 0.843 & 0.959 \\
\hline
\end{tabular}

Obs: Coeficientes com dois asteriscos indicam significância a 5\%. Com um asterisco indica significância a $10 \%$. Estatística t entre parênteses.

A variável introduzida por nós para explicar o comportamento da oferta de moeda, $C B C_{A M t}$ (crédito concedido pela Autoridade Monetária aos Bancos Comerciais - operação de redesconto dentro de um Banco Central), não foi significativa em nenhum dos três períodos. Por outro lado, em medida oposta, o crédito concedido pelo Banco do Brasil enquanto Autoridade Monetária $\left(C B B_{A M t}\right)$ foi significante nos três períodos. $\mathrm{O}$ crédito concedido pelos Bancos Comerciais $\left(C B C_{t}\right)$ só foi significante em um período (1960:01-1963:11), o mesmo ocorrendo com as Reservas Internacionais $\left(R_{t}\right)$, só que em outro período (1965:07 - 1968:12).

Na verdade, a mudança na política monetária durante o PAEG só pode ser associada a duas variáveis: $C B B_{A M t}$ e $R_{t}$. No primeiro momento, ao contrário do que se possa ima- 
ginar, o comportamento do crédito do Banco do Brasil enquanto Autoridade Monetária foi o responsável pelo comportamento da oferta de moeda (o controle só começou a ocorrer após junho de 1965). Cysne (1993) afirmou que o Banco do Brasil provocou o descontrole antes de 1966, não especificando exatamente o momento. Pastore (1973, 1973a) observou bem que os empréstimos do Banco do Brasil ainda continuaram elevados em 1964, caíram em 1965, mas pecou ao informar ter havido uma estabilidade num patamar mais baixo em 1966 (não houve quebra estrutural em 1966 - o coeficiente era o mesmo de 1965). Lara Resende subestimou totalmente a força do Banco do Brasil ao considerar o seu papel no descontrole monetário após o início de 1966.

Para as Reservas Internacionais $\left(R_{t}\right)$, guardamos um capítulo à parte. É preciso entender como uma conta do Ativo da Autoridade Monetária apresentou um sinal negativo quando deveria apresentar um sinal positivo. Nossa investigação nos relatórios da SUMOC indicou uma perda constante de reservas no período que vai de 1958 até agosto de 1966. Lara Resende (1982) mostrou, em dólares, que as reservas atingiram seu pior nível em 1963 (219 milhões de dólares) e a partir daí começam a se recuperar até 1966. Em 1967 houve nova queda. Para Pastore (1973a e 1973), houve uma perda de reservas a partir do segundo trimestre de 1962, que só parou no segundo trimestre de 1964. Do primeiro trimestre de 1966 até o segundo trimestre de 1968 novas perdas ocorreram. A correlação negativa entre a variação de reservas e a oferta de moeda foi determinada por esta situação especial.

\section{CONCLUSÕES E PONTOS FUNDAMENTAIS DA INVESTIGAÇÃO}

Do que acabamos de descrever sobre a influência das variáveis descritas como relevantes na determinação da oferta de moeda no período que envolve o PAEG, temos a dizer que:

1. A variável mais importante para explicar o descontrole da oferta de moeda durante o PAEG foi o crédito concedido pelo Banco do Brasil enquanto Autoridade Monetária. Cysne (1982) e Pastore (1973, 1973a) acertaram ao afirmar esta importância, embora não especifiquem exatamente quando o controle ocorreu (a partir de julho de 1965). Lara Resende (1982) negligenciou totalmente a importância do Banco do Brasil no descontrole monetário (disse que ele foi importante a partir de 1966 para explicar o descontrole).

2. As Reservas Internacionais não tiveram qualquer participação no descontrole da oferta de moeda: primeiro, porque elas só foram significantes para explicar a oferta de moeda a partir de $1966 \mathrm{e}$, segundo, porque as reservas estiveram, de acordo com levantamento efetuado por nós nas contas da SUMOC, negativas de 1958 até 
agosto de 1966 (acarretou uma correlação negativa da série reservas e da oferta de moeda).

3. Cysne (1993) não demonstrou qualquer participação das Reservas no processo de descontrole monetário, Pastore (1973, 1973a) destacou sua importância basicamente entre o final de 1964 e início de 1966 (ele não observou os dados da SUMOC, estimou as reservas em cruzeiros) e Lara Resende (1982) errou totalmente ao jogar o peso do descontrole nas reservas (seus dados de reserva estavam em dólares).

4. Os Bancos Comerciais não tiveram qualquer importância no descontrole da oferta de moeda durante o PAEG. O que se pode dizer é que mesmo antes do PAEG o comportamento dos Bancos Comerciais na determinação da oferta de moeda (novembro de 1963) já não era mais significante.

\section{REFERÊNCIAS}

ABREU, M. A. (org.). A ordem do progresso. Editora Campus,1990.

ANDREWS, D. W. K. Tests for parameter instability and structural change with unknown change point.' Econometrica, v. 61, n. 4, p. 821-856, 1993.

BAER, W. A economia brasileira. São Paulo: Nobel, 1996.

BEAULIEU, J. J.; MIRON, J. A. Seasonal unit roots in aggregate data. Journal of Econometrics, 55, p. 305-328, 1993.

BRUNNER, K.; MELTZER, A. Some further investigations of supply and demand functions for money. The Journal of Finance, v. 19, n. 2, part 1: Papers and Proceedings of the Twenty-Second Annual Meeting of the American Finance Association, 1964.

CYSNE, R. P. A economia brasileira no período militar. Texto para discussão interna, 227. FGV/EAESP, 1993.

DICKEY, D. A.; FULLER, W. A. Distribution of estimators for autoregressive time series with a unit root. Journal of American Statistical Association, 74, p. 427-431, 1974.

. Likelihood ratio tests for autoregressive time series with a unit root. Econometrica, 49, p. 1057-1072, 1981.

ELLIOTT, G.; ROTHEMBERG, T. J.; STOCK, H. Efficient tests for an autoregressive unit root. Econometrica, 64, p. 813-836, 1996.

FRANSES, P. H., McALEER, M. Cointegration analysis of seasonal time series. Journal of Economic Surveys, v.12, n. 5, p. 651-678, 1998a. 
. Testing for unit roots and seasonal transformation. Journal of Time Series Analysis, v. 19, n. 2, p. 147-164, 1998b.

HAMILTON, J. D. Time series analysis. Princeton University Press, 1994.

HYLLEBERG, S.; ENGLE, R. F.; GRANGER, C. W. J.; YOO, B. S. Seasonal integration and cointegration. Journal of Econometrics 44, p. 215-238, 1990.

IMF. Estadisticas financieras internacionales. Vários números.

JOHANSEN, S.; JUSELIUS, K. Maximum likelihood estimation and inference on cointegration - with applications to the demand for money. Oxford Bulletin of Economics and Statistics, v. 52, n. 2, 1990.

JOHANSEN, S.; SCHAUMBURG, E. Likelihood analysis of seasonal cointegration. Journal of Econometrics 88, p. 301-339, 1999.

KWIATKOWSKI, D.; PHILLIPS, P. C. B.; SCHMIDT, P.; SCHIN, Y. Testing the null hypothesis of stationarity against the alternative of a unit root: how sure are we that economic time series have a unit root? Journal of Econometrics 54, p. 159-178, 1992.

LARA RESENDE, A. A política brasileira de estabilização: 1963/68. Politica e Planejamento Econômico, v. 12, n. 3, 1982.

LANGONI, C. G. A study in economic growth: the Brazilian case. 1970. Tese (Doutorado). Universidade de Chicago.

LEE, H. S. Maximum likelihood inference on cointegration and seasonal cointegration. Journal of Econometrics 54, p. 1-47, 1992.

MARTÍN, E. C.; DÍAZ-EMPARANZA. Estimación y contraste de velaciones de cointegración con datos mensuales fuertemente estacionales. 1996. Mimeografado.

MELTZER, A. The behavior of the French money supply: 1938-54. The Journal of Political Economy, v. 67, n. 3, 1959.

NG, S.; PERRON, P. Lag length selection and the construction of unit root tests with good size and power. Econometrica, v. 69, n. 6, p. 1519-1554, 2001.

PASTORE, A. C. A oferta de moeda no Brasil - 1961/72. Pesquisa e Planejamento Econômico, v. 3, n. 4, 1973.

. Aspectos da política monetária recente no Brasil. Estudos Econômicos, v. 3, n. 3, p. 7-58, set./dez. 1973a.

PHILLIPS, P. C. B.; PERRON, P. Testing for unit roots in time series regressions. Biometrika 75, p. 335-346, 1988.

PHILlIPS, P. C. B.; XIAO, Z. A primer on unit root testing. Cowles Foundation Paper 972, 1999.

PINDICK, R. S.; RUBINFELD, D. L. Econometric methods and economic forecasts. MacGraw-Hill, 1998.

SARGENT, T. The end of four big inflations. In: HALL, Robert E. (eds.), Inflation. Chicago: University of Chicago Press, 1982. 
SARGENT, T.; WALLACE, N. Rational expectations in optimal monetary instrument, and the optimal money supply rule. Journal of Political Economy, 83, 1975.

SERRA, J. Ciclos e mudanças estruturais na economia brasileira de após-guerra: a crise recente. Revista de Economia Politica, v. 2/2, 1982.

SIMONSEN, M. H.; CYSNE, R. P. Macroeconomia. Editora ao Livro-Técnico, 1992.

SUMOC. Revista da SUMOC. Vários números.

ZIVOT, E.; ANDREWS, W. K. Further evidence on the great crash, the oil-price shock, and the unit root process. Journal of Business and Economic Statistics, v. 10 n. 3, p. 25-44, July 1992.

\section{A. APENDICE}

\section{A.1 Indicadores Macroeconômicos do Período}

INFLAÇÃO, TAXA DE CRESCIMENTO DO PRODUTO E SALDO EM TRANSAÇOEES CORRENTES

\begin{tabular}{lcrc}
\hline Anos & IGP-DI (Var. \%) & PNB & Saldo em Transações Correntes \\
\hline 1960 & 29,2 & 9,7 & -478 \\
1961 & 37,0 & 10,3 & -222 \\
1962 & 51,6 & 5,2 & -398 \\
1963 & 75,4 & 1,6 & -114 \\
\hline
\end{tabular}

Fonte: LARA RESENDE (1982).

Obs: Índice Geral de Preços- Disponibilidade Interna (IGP-DI), Produto Nacional Bruto (PNB) e Saldo em Transaçốes Correntes (US\$ milhôes - FOB). 
A.2 Estatísticas Descritivas e Gráficos das Séries

ESTATÍSTICAS DESCRITIVAS DAS SÉRIES

\begin{tabular}{lrrrrr}
\hline & $C B C_{\text {AMt }}$ & \multicolumn{1}{c}{$C B B_{\text {AMt }}$} & \multicolumn{1}{c}{$L M_{1 t}$} & \multicolumn{1}{c}{$R_{t}$} & \multicolumn{1}{c}{$C B C_{t}$} \\
\hline Média & 18,142 & 266,763 & 540,745 & $-1786,441$ & 132,889 \\
Mediana & 18,799 & 256,809 & 514,421 & $-2075,716$ & 129,118 \\
Máximo & 33,450 & 448,257 & 751,582 & 91,751 & 207,087 \\
Mínimo & 6,896 & 202,569 & 448,165 & $-7199,498$ & 102,630 \\
Desvio Padrão & 4,883 & 53,569 & 74,034 & 1473,034 & 20,401 \\
Assimetria & 0,234 & 1,474 & 0,940 & $-0,287$ & 1,713 \\
Curtose & 4,219 & 5,103 & 2,865 & 3,095 & 6,379 \\
№ de Observações & 108 & 108 & 108 & 108 & 108 \\
\hline
\end{tabular}

\section{GRÁFICOS DAS SÉRIES}
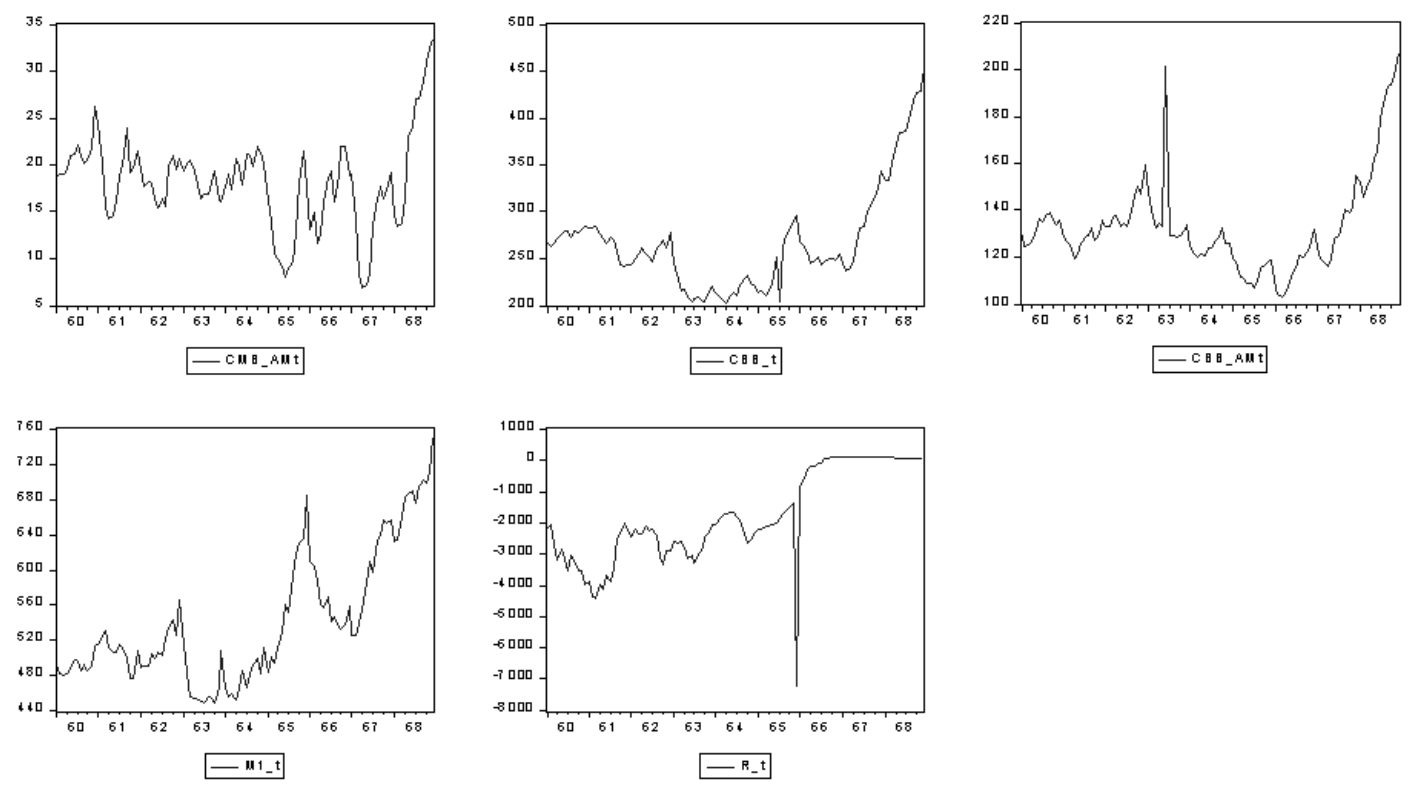

Est. econ., São Paulo, 35(3): 391-431, jul-set 2005 


\section{A.3 Resultados Teste Raiz Unitária}

RESULTADOS DOS TESTES DE RAIZ UNITÁRIA - CBC

\begin{tabular}{|c|c|c|c|}
\hline & & Nível & Primeira Diferença \\
\hline \multirow[t]{2}{*}{ ADF } & Est. Teste & $-2,726$ & $-7,908$ \\
\hline & Valor Crítico 5\% & $-3,453$ & $-3,453$ \\
\hline \multirow[t]{2}{*}{ PP } & Est. Teste & $-2,155$ & $-7,746$ \\
\hline & Valor Crítico 5\% & $-3,453$ & $-3,453$ \\
\hline \multirow[t]{2}{*}{ DF-GLS } & Est. Teste & $-2,890$ & $-7,932$ \\
\hline & Valor Crítico 5\% & $-3,024$ & $-3,024$ \\
\hline \multirow[t]{2}{*}{ KPSS } & Est. Teste & 0,142 & 0,089 \\
\hline & Valor Crítico 5\% & 0,146 & 0,146 \\
\hline \multirow[t]{2}{*}{ ERS } & Est. Teste & 5,497 & 1,820 \\
\hline & Valor Crítico 5\% & 5,642 & 5,641 \\
\hline \multirow[t]{2}{*}{ Ng-Perron } & Est. $M Z_{A}$ & $-21,285$ & $-49,961$ \\
\hline & Valor Crítico $5 \% M Z_{A}$ & $-17,300$ & $-17,300$ \\
\hline \multirow[t]{2}{*}{$\mathrm{Ng}$-Perron } & Est. $M Z_{t}$ & $-3,034$ & $-4,997$ \\
\hline & Valor Crítico 5\% MZ & $-2,910$ & $-2,910$ \\
\hline \multirow[t]{2}{*}{ Ng-Perron } & Est. MSB & 0,143 & 0,100 \\
\hline & Valor Crítico 5\% MSB & 0,168 & 0,168 \\
\hline \multirow[t]{2}{*}{ Ng-Perron } & Est. MPT & 5,645 & 1,828 \\
\hline & Valor Crítico 5\% MPT & 5,480 & 5,480 \\
\hline
\end{tabular}

Obs: Teste ADF Realizado com Constante e Tendência. Seleção do número de defasagens utilizada na regressão auxiliar realizada pelo critério de $S$ chwartz (1 defasagem no teste em nível e 0 defasagens no teste em primeira diferença). Teste PP Realizado com Constante e Tendência. Seleção do Estimador de Densidade Espectral: Método de Bartlett (largura de banda 4 no teste em nível e 11 no teste em primeira defasagem). Teste DF-GLS com constante e tendência e seleção de defasagens na regressão auxiliar com o critétio de Schwartz (1 defasagem no teste em nível e 0 defasagens no teste em primeira diferença). Teste KPSS realizado com Constante e Tendência, Método de Bartlett (largura de banda 7 no teste em nível e $8 \mathrm{em}$ primeira diferença). Teste ERS realizado com seleção AR do estimador da densidade espectral, com constante e tendência. Seleção de defasagens pelo critério de Schwartz (1 defasagem no teste em nível e nenhuma defasagem no teste em primeira diferença). Testes $\mathrm{Ng}$-Perron realizados com a eliminação de tendência por GLS e seleção de defasagens adicionais pelo critério de Schwartz. 
RESULTADOS DOS TESTES DE RAIZ UNITÁRIA - CBB

\begin{tabular}{|c|c|c|c|}
\hline & & Nível & Primeira Diferença \\
\hline \multirow[t]{2}{*}{ ADF } & Est. Teste & 0,457 & $-11,548$ \\
\hline & Valor Crítico 5\% & $-3,452$ & $-3,453$ \\
\hline \multirow[t]{2}{*}{ PP } & Est. Teste & 0,548 & $-11,457$ \\
\hline & Valor Crítico 5\% & $-3,453$ & $-3,453$ \\
\hline \multirow[t]{2}{*}{ DF-GLS } & Est. Teste & 0,038 & $-11,463$ \\
\hline & Valor Crítico 5\% & $-3,023$ & $-3,024$ \\
\hline \multirow[t]{2}{*}{ KPSS } & Est. Teste & 0,280 & 0,108 \\
\hline & Valor Crítico 5\% & 0,146 & 0,146 \\
\hline \multirow[t]{2}{*}{ ERS } & Est. Teste & 50,686 & 1,838 \\
\hline & Valor Crítico 5\% & 5,642 & 5,641 \\
\hline \multirow[t]{2}{*}{ Ng-Perron } & Est. $M Z_{A}$ & 0,172 & $-54,474$ \\
\hline & Valor Crítico $5 \% M Z_{A}$ & $-17,300$ & $-17,300$ \\
\hline \multirow[t]{2}{*}{ Ng-Perron } & Est. $M Z_{t}$ & 0,070 & $-5,200$ \\
\hline & Valor Crítico 5\% $M Z_{t}$ & $-2,910$ & $-2,910$ \\
\hline \multirow[t]{2}{*}{ Ng-Perron } & Est. MSB & 0,408 & 0,095 \\
\hline & Valor Crítico 5\% MSB & 0,168 & 0,168 \\
\hline \multirow[t]{2}{*}{ Ng-Perron } & Est. MPT & 45,564 & 1,764 \\
\hline & Valor Crítico 5\% MPT & 5,480 & 5,480 \\
\hline
\end{tabular}

Obs: Teste ADF Realizado com Constante e Tendência. Seleção do número de defasagens utilizada na regressão auxiliar realizada pelo critério de $S c h w a r t z$ ( 0 defasagens no teste em nível e 0 defasagens no teste em primeira diferença). Teste PP Realizado com Constante e Tendência. Seleção do Estimador de Densidade Espectral: Método de Bartlett (largura de banda 4 no teste em nível e 4 no teste em primeira defasagem). Teste DF-GLS com constante e tendência e seleção de defasagens na regressão auxiliar com o critério de Schwartz (0 defasagens no teste em nível e 0 defasagens no teste em primeira diferença). Teste KPSS realizado com Constante e Tendência, Método de Bartlett (largura de banda 8 no teste em nível e 4 em primeira diferença). Teste ERS realizado com seleção AR do estimador da densidade espectral, com constante e tendência. Seleção de defasagens pelo critério de Schwartz (0 defasagens no teste em nível e nenhuma defasagem no teste em primeira diferença). Testes $\mathrm{Ng}$-Perron realizados com a eliminação de tendência por GLS e seleção de defasagens adicionais pelo critério de Schwartz. 
RESULTADOS DOS TESTES DE RAIZ UNITÁRIA - $R_{t}$

\begin{tabular}{llcc}
\hline & & Nível & Primeira Diferença \\
\hline ADF & Est. Teste & $-3,267$ & $-16,356$ \\
PP & Valor Crítico 5\% & $-3,454$ & $-3,453$ \\
\multirow{2}{*}{ DF-GLS } & Est. Teste & $-6,562$ & $-23,037$ \\
& Valor Crítico 5\% & $-3,453$ & $-3,453$ \\
KPSS & Est. Teste & $-3,157$ & $-10,838$ \\
& Valor Crítico 5\% & $-3,024$ & $-3,024$ \\
ERS & Est. Teste & 0,132 & 0,147 \\
& Valor Crítico 5\% & 0,146 & 0,146 \\
Ng-Perron & Est. Teste & 3,756 & 1,307 \\
& Valor Crítico 5\% & 5,642 & 5,641 \\
Ng-Perron & Est. $M Z_{A}$ & $-16,483$ & $-57,380$ \\
& Valor Crítico 5\% MZ & $-17,300$ & $-17,300$ \\
Ng-Perron & Est. $M Z_{t}$ & $-2,867$ & $-5,356$ \\
& Valor Crítico 5\% MZ & $-2,910$ & $-2,910$ \\
Ng-Perron & Est. MSB & 0,174 & 0,094 \\
& Valor Crítico 5\% MSB & 0,168 & 0,168 \\
& Est. MPT & 5,550 & 1,588 \\
& Valor Crítico 5\% MPT & 5,480 & 5,480 \\
\hline
\end{tabular}

Obs: Teste ADF Realizado com Constante e Tendência. Seleção do número de defasagens utilizada na regressão auxiliar realizada pelo critério de Schwartz modificado (4 defasagens no teste em nível e 0 defasagens no teste em primeira diferença). Teste PP Realizado com Constante e Tendência. Seleção do Estimador de Densidade Espectral: Método de Bartlett (largura de banda 5 no teste em nível e 15 no teste em primeira defasagem). Teste DF-GLS com constante e tendência e seleção de defasagens na regressão auxiliar com o critério de Schwartz (1 defasagem no teste em nível e 1 defasagem no teste em primeira diferença). Teste KPSS realizado com Constante e Tendência, Método de Bartlett (largura de banda 7 no teste em nível e 4 em primeira diferença). Teste ERS realizado com seleção AR do estimador da densidade espectral, com constante e tendência. Seleção de defasagens pelo critério de Schwartz ( 0 defasagens no teste em nível e 1 defasagem no teste em primeira diferença). Testes Ng-Perron realizados com a eliminação de tendência por GLS e seleção de defasagens adicionais pelo critério de Schwartz. 
RESULTADOS DOS TESTES DE RAIZ UNITÁRIA - CBC $t_{t}$

\begin{tabular}{llcc}
\hline & & Nível & Primeira Diferença \\
\hline ADF & Est. Teste & $-0,408$ & $-15,325$ \\
PP & Valor Crítico 5\% & $-3,452$ & $-3,453$ \\
& Est. Teste & $-1,087$ & $-16,827$ \\
DF-GLS & Valor Crítico 5\% & $-3,453$ & $-3,453$ \\
& Est. Teste & $-0,982$ & $-15,036$ \\
KPSS & Valor Crítico 5\% & $-3,023$ & $-3,024$ \\
& Est. Teste & 0,202 & 0,153 \\
ERS & Valor Crítico 5\% & 0,146 & 0,146 \\
& Est. Teste & 21,456 & 2,062 \\
Ng-Perron & Valor Crítico 5\% & 5,642 & 5,641 \\
& Est. $M Z_{A}$ & $-3,441$ & $-45,094$ \\
\multirow{2}{*}{ Ng-Perron } & Valor Crítico 5\% MZ & $-17,300$ \\
& Est. $M Z_{t}$ & $-17,300$ & $-4,743$ \\
\multirow{2}{*}{ Ng-Perron } & Valor Crítico 5\% MZ & $-0,912$ & $-2,910$ \\
& Est. $M S B$ & $-2,910$ & 0,105 \\
\multirow{2}{*}{ Ng-Perron } & Valor Crítico 5\% MSB & 0,265 & 0,168 \\
& Est. $M P T$ & 0,168 & 2,047 \\
& Valor Crítico 5\% MPT & 20,217 & 5,480 \\
\hline
\end{tabular}

Obs: Teste ADF Realizado com Constante e Tendência. Seleção do número de defasagens utilizada na regressão auxiliar realizada pelo critério de $S$ chwartz ( 1 defasagens no teste em nível e 0 defasagens no teste em primeira diferença). Teste PP Realizado com Constante e Tendência. Seleção do Estimador de Densidade Espectral: Método de Bartlett (largura de banda 2 no teste em nível e 14 no teste em primeira defasagem). Teste DF-GLS com constante e tendência e seleção de defasagens na regressão auxiliar com o critério de Schwartz ( 1 defasagens no teste em nível e 0 defasagens no teste em primeira diferença). Teste KPSS realizado com Constante e Tendência, Método de Bartlett (largura de banda 8 no teste em nível e 16 em primeira diferença). Teste ERS realizado com seleção AR do estimador da densidade espectral, com constante e tendência. Seleção de defasagens pelo critério de Schwartz (1 defasagem no teste em nível e nenhuma defasagem no teste em primeira diferença). Testes $\mathrm{Ng}$-Perron realizados com a eliminação de tendência por GLS e seleção de defasagens adicionais pelo critério de Schwartz 
RESULTADOS DOS TESTES DE RAIZ UNITÁRIA - LM ${ }_{1 t}$

\begin{tabular}{llcc}
\hline & & Nível & Primeira Diferença \\
\hline ADF & Est. Teste & $-1,487$ & $-11,311$ \\
PP & Valor Crítico 5\% & $-3,452$ & $-3,453$ \\
& Est. Teste & $-1,573$ & $-11,271$ \\
DF-GLS & Valor Crítico 5\% & $-3,453$ & $-3,453$ \\
& Est. Teste & $-1,467$ & $-10,773$ \\
KPSS & Valor Crítico 5\% & $-3,023$ & $-3,024$ \\
& Est. Teste & 0,213 & 0,044 \\
ERS & Valor Crítico 5\% & 0,146 & 0,146 \\
& Est. Teste & 16,857 & 2,007 \\
Ng-Perron & Valor Crítico 5\% & 5,642 & 5,641 \\
& Est. $M Z_{A}$ & $-5,526$ & $-51,915$ \\
Ng-Perron & Valor Crítico 5\% MZ & $-17,300$ & $-17,300$ \\
& Est. $M Z_{t}$ & $-1,409$ & $-5,056$ \\
Ng-Perron & Valor Crítico 5\% MZ & $-2,910$ & $-2,910$ \\
& Est. $M S B$ & 0,255 & 0,097 \\
Ng-Perron & Valor Crítico 5\% MSB & 0,168 & 0,168 \\
& Est. MPT & 15,891 & 1,945 \\
& Valor Crítico 5\% MPT & 5,480 & 5,480 \\
\hline
\end{tabular}

Obs: Teste ADF Realizado com Constante e Tendência. Seleção do número de defasagens utilizada na regressão auxiliar realizada pelo critério de $S$ chwartz ( 0 defasagens no teste em nível e 0 defasagens no teste em primeira diferença). Teste PP Realizado com Constante e Tendência. Seleção do Estimador de Densidade Espectral: Método de Bartlett (largura de banda 5 no teste em nível e 4 no teste em primeira defasagem). Teste DF-GLS com constante e tendência e seleção de defasagens na regressão auxiliar com o critério de Schwartz ( 0 defasagens no teste em nível e 0 defasagens no teste em primeira diferença). Teste KPSS realizado com Constante e Tendência, Método de Bartlett (largura de banda 8 no teste em nível e 4 em primeira diferença). Teste ERS realizado com seleção AR do estimador da densidade espectral, com constante e tendência. Seleção de defasagens pelo critério de Schwartz $(0$ defasagens no teste em nível e nenhuma defasagem no teste em primeira diferença). Testes $\mathrm{Ng}$-Perron realizados com a eliminação de tendência por GLS e seleção de defasagens adicionais pelo critério de Schwartz. 


\section{A.4 Testes de Raiz Unitária com Quebra Estrutural Endógena}

RESULTADOS DO TESTE ZIVOT E ANDREWS (1992) - CBC $A M t$

\begin{tabular}{llcc}
\hline & Tipo de Quebra & Est. Teste & Valor Crítico 5\% \\
\hline \multirow{3}{*}{ Nível } & Intercepto & $-2,598$ & $-3,77$ \\
& Tendência & $-2,577$ & $-3,95$ \\
& Tendência e Intercepto & $-2,579$ & $-3,99$ \\
\hline \multirow{2}{*}{$1^{\text {a }}$ Diferença } & Intercepto & $-6,621$ & $-3,77$ \\
& Tendência & $-6,654$ & $-3,80$ \\
& Tendência e Intercepto & $-6,635$ & $-3,99$ \\
\hline
\end{tabular}

RESULTADOS DO TESTE ZIVOT E ANDREWS (1992) - CBB $A M t$

\begin{tabular}{llcc}
\hline & Tipo de Quebra & Est. Teste & Valor Crítico 5\% \\
\hline \multirow{3}{*}{ Nível } & Intercepto & 2,030 & $-3,77$ \\
& Tendência & 1,483 & $-3,85$ \\
& Tendência e Intercepto & 0,749 & $-3,75$ \\
\hline \multirow{3}{*}{ a $^{\text {a }}$ Diferença } & Intercepto & $-6,056$ & $-3,68$ \\
& Tendência & $-6,631$ & $-3,95$ \\
& Tendência e Intercepto & $-6,592$ & $-3,80$ \\
\hline
\end{tabular}

RESULTADOS DO TESTE ZIVOT E ANDREWS (1992) $-R_{t}$

\begin{tabular}{llcc}
\hline & Tipo de Quebra & Est. Teste & Valor Crítico 5\% \\
\hline \multirow{3}{*}{ Nível } & Intercepto & $-1,793$ & $-3,68$ \\
& Tendência & $-4,250$ & $-3,65$ \\
& Tendência e Intercepto & $-4,394$ & $-3,75$ \\
\hline \multirow{3}{*}{ 1․ Diferença } & Intercepto & $-10,838$ & $-3,77$ \\
& Tendência & $-10,800$ & $-3,49$ \\
& Tendência e Intercepto & $-10,648$ & $-4,18$ \\
\hline
\end{tabular}

RESULTADOS DO TESTE ZIVOT E ANDREWS (1992) - CBC $C_{t}$

\begin{tabular}{llcc}
\hline & Tipo de Quebra & Est. Teste & Valor Crítico 5\% \\
\hline \multirow{3}{*}{ Nível } & Intercepto & $-0,002$ & $-3,76$ \\
& Tendência & $-0,184$ & $-3,95$ \\
& Tendência e Intercepto & $-0,396$ & $-3,75$ \\
\hline \multirow{3}{*}{$1^{\text {a }}$ Diferença } & Intercepto & $-9,238$ & $-3,68$ \\
& Tendência & $-9,470$ & $-3,65$ \\
& Tendência e Intercepto & $-9,450$ & $-3,75$ \\
\hline
\end{tabular}


RESULTADOS DO TESTE ZIVOT E ANDREWS (1992) - LM $M_{1 t}$

\begin{tabular}{llcc}
\hline & Tipo de Quebra & Est. Teste & Valor Crítico 5\% \\
\hline \multirow{3}{*}{ Nível } & Intercepto & 0,674 & $-3,80$ \\
& Tendência & $-0,202$ & $-3,85$ \\
& Tendência e Intercepto & $-1,203$ & $-3,75$ \\
1a Diferença & Intercepto & $-6,610$ & $-3,68$ \\
& Tendência & $-6,686$ & $-3,96$ \\
& Tendência e Intercepto & $-6,665$ & $-3,80$ \\
\hline
\end{tabular}

EVOLUÇÃO DA ESTATÍSTICA DE TESTE - VARIÁVEL $R_{t}$

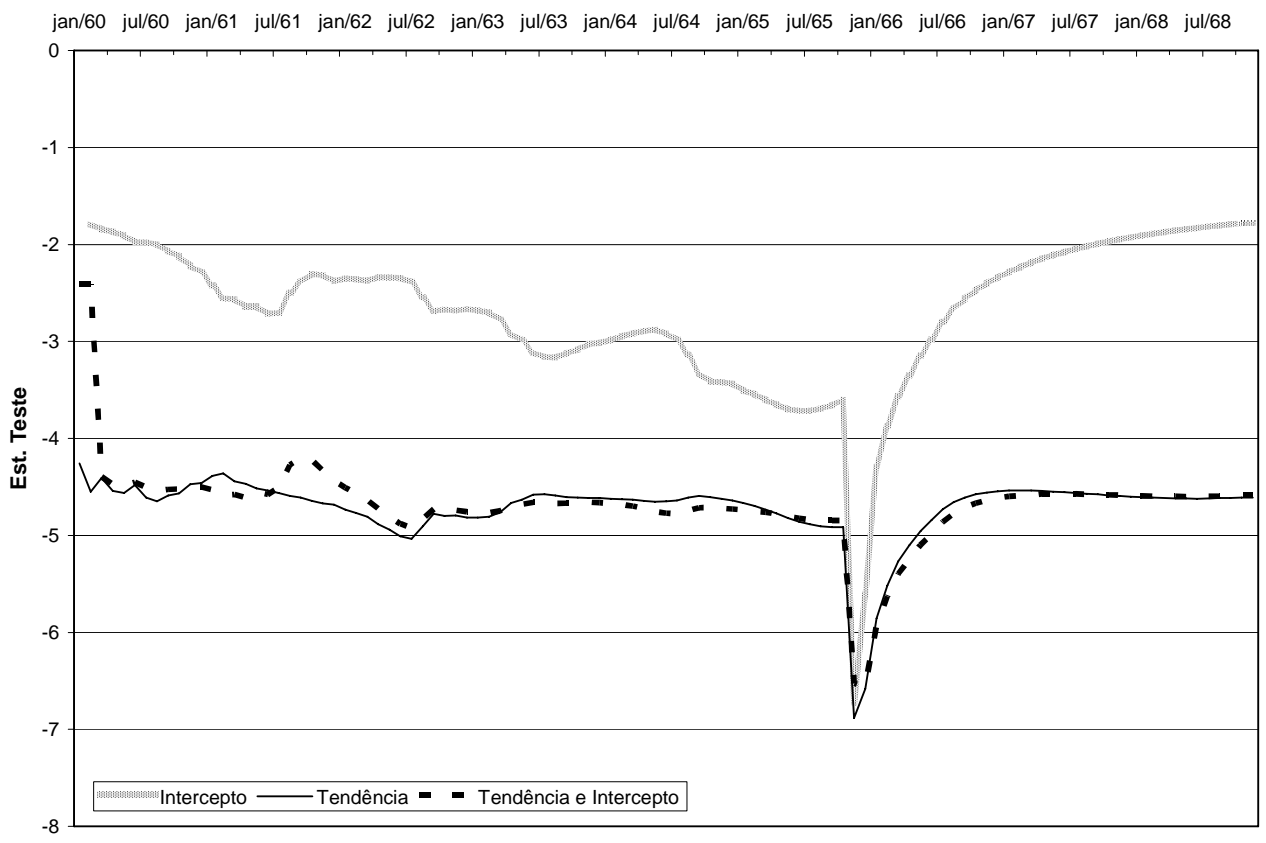




\section{A.5 Resultados dos Testes de Raiz Unitária Sazonal}

\section{RESULTADOS DO TESTE BEAULIEU E MIRON (1993) - CBC $A M t$}

\begin{tabular}{cccccc}
\hline Variável & Est. Teste & Valor Crítico - 5\% & Variável & Est. Teste & Valor Crítico - 5\% \\
\hline$\pi_{1}$ & $-6,597$ & $-3,28$ & $\pi_{7}$ & $-4,570$ & $-3,24$ \\
$\pi_{2}$ & $-2,714$ & $-2,75$ & $\pi_{8}$ & $-9,466$ & $-1,84$ \\
$\pi_{3}$ & 4,178 & $-3,24$ & $\pi_{9}$ & $-7,869$ & $-3,24$ \\
$\pi_{4}$ & 0,431 & 1,84 & $\pi_{10}$ & 0,315 & 1,84 \\
$\pi_{5}$ & $-2,945$ & $-3,24$ & $\pi_{11}$ & 6,270 & $-3,24$ \\
$\pi_{6}$ & 8,476 & 1,84 & $\pi_{12}$ & 0,447 & 1,84
\end{tabular}

Obs: Testes realizados com uma defasagem da variável dependente na regressão auxiliar.

RESULTADOS DO TESTE BEAULIEU E MIRON (1993) - CBB

\begin{tabular}{cccccc}
\hline Variável & Est. Teste & Valor Crítico - 5\% & Variável & Est. Teste & Valor Crítico - 5\% \\
\hline$\pi_{1}$ & $-6,879$ & $-3,28$ & $\pi_{7}$ & $-3,732$ & $-3,24$ \\
$\pi_{2}$ & $-2,752$ & $-2,75$ & $\pi_{8}$ & $-7,452$ & $-1,85$ \\
$\pi_{3}$ & 1,157 & $-3,24$ & $\pi_{9}$ & $-6,176$ & $-3,24$ \\
$\pi_{4}$ & $-1,261$ & $-1,85$ & $\pi_{10}$ & 1,014 & 1,85 \\
$\pi_{5}$ & $-4,761$ & $-3,24$ & $\pi_{11}$ & 2,877 & $-3,24$ \\
$\pi_{6}$ & 6,769 & 1,85 & $\pi_{12}$ & $-2,119$ & $-1,85$ \\
\hline
\end{tabular}

Obs: Testes realizados com uma defasagem da variável dependente na regressão auxiliar.

RESULTADOS DO TESTE BEAULIEU E MIRON (1993) - CBC ${ }_{t}$

\begin{tabular}{cccccc}
\hline Variável & Est. Teste & Valor Crítico - 5\% & Variável & Est. Teste & Valor Crítico - 5\% \\
\hline$\pi_{1}$ & $-4,853$ & $-3,28$ & $\pi_{7}$ & $-1,349$ & $-3,24$ \\
$\pi_{2}$ & $-1,479$ & $-2,75$ & $\pi_{8}$ & $-5,775$ & $-1,85$ \\
$\pi_{3}$ & 0,602 & $-3,24$ & $\pi_{9}$ & $-5,656$ & $-3,24$ \\
$\pi_{4}$ & $-0,521$ & $-1,85$ & $\pi_{10}$ & 1,817 & 1,85 \\
$\pi_{5}$ & $-5,131$ & $-3,24$ & $\pi_{11}$ & 1,524 & $-3,24$ \\
$\pi_{6}$ & 6,244 & 1,85 & $\pi_{12}$ & $-3,927$ & $-1,85$ \\
\hline
\end{tabular}

Obs: Testes realizados com uma defasagem da variável dependente na regressão auxiliar. 
RESULTADOS DO TESTE BEAULIEU E MIRON (1993) - $R_{t}$

\begin{tabular}{cccccc}
\hline Variável & Est. Teste & Valor Crítico - 5\% & Variável & Est. Teste & Valor Crítico - 5\% \\
\hline$\pi_{1}$ & $-5,297$ & $-3,28$ & $\pi_{7}$ & $-2,454$ & $-3,24$ \\
$\pi_{2}$ & $-2,648$ & $-2,75$ & $\pi_{8}$ & $-5,355$ & $-1,85$ \\
$\pi_{3}$ & 0,784 & $-3,24$ & $\pi_{9}$ & $-6,279$ & $-3,24$ \\
$\pi_{4}$ & $-0,229$ & $-1,85$ & $\pi_{10}$ & 1,127 & 1,85 \\
$\pi_{5}$ & $-5,700$ & $-3,24$ & $\pi_{11}$ & 1,171 & $-3,24$ \\
$\pi_{6}$ & 6,763 & 1,85 & $\pi_{12}$ & $-2,384$ & $-1,85$
\end{tabular}

Obs: Testes realizados com uma defasagem da variável dependente na regressão auxiliar.

RESULTADOS DO TESTE BEAULIEU E MIRON (1993) - LM

\begin{tabular}{cccccc}
\hline Variável & Est. Teste & Valor Crítico - 5\% & Variável & Est. Teste & Valor Crítico - 5\% \\
\hline$\pi_{1}$ & $-8,126$ & $-3,28$ & $\pi_{7}$ & $-4,308$ & $-3,24$ \\
$\pi_{2}$ & $-1,792$ & $-2,75$ & $\pi_{8}$ & $-8,502$ & $-1,84$ \\
$\pi_{3}$ & 1,896 & $-3,24$ & $\pi_{9}$ & $-7,307$ & $-3,24$ \\
$\pi_{4}$ & $-1,337$ & $-1,84$ & $\pi_{10}$ & 0,958 & 1,84 \\
$\pi_{5}$ & $-4,263$ & $-3,24$ & $\pi_{11}$ & 5,115 & $-3,24$ \\
$\pi_{6}$ & 8,021 & 1,84 & $\pi_{12}$ & $-0,052$ & $-1,84$ \\
\hline
\end{tabular}

Obs: Testes realizados com uma defasagem da variável dependente na regressão auxiliar.

Este documento foi transformado do LATEX por HEVEA.

Agradecemos ao Professor José Benedito Zarzuela Maia, chefe do Departamento Econômico do Banco Central em São Paulo, pela cessão dos dados, e ao aluno Guilherme Parente Martins Ferreira, pelo trabalho de levantamento dos mesmos. Além disso, gostaríamos de agradecer aos pareceristas anônimos pelas inúmeras contribuições levantadas a versões anteriores deste artigo.

(Recebido em julho de 2003. Aceito para publicação em março de 2005). 